\title{
Evaluation and transcriptome analysis of the novel oleaginous microalga Lobosphaera bisecta (Trebouxiophyceae, Chlorophyta) for arachidonic acid production
}

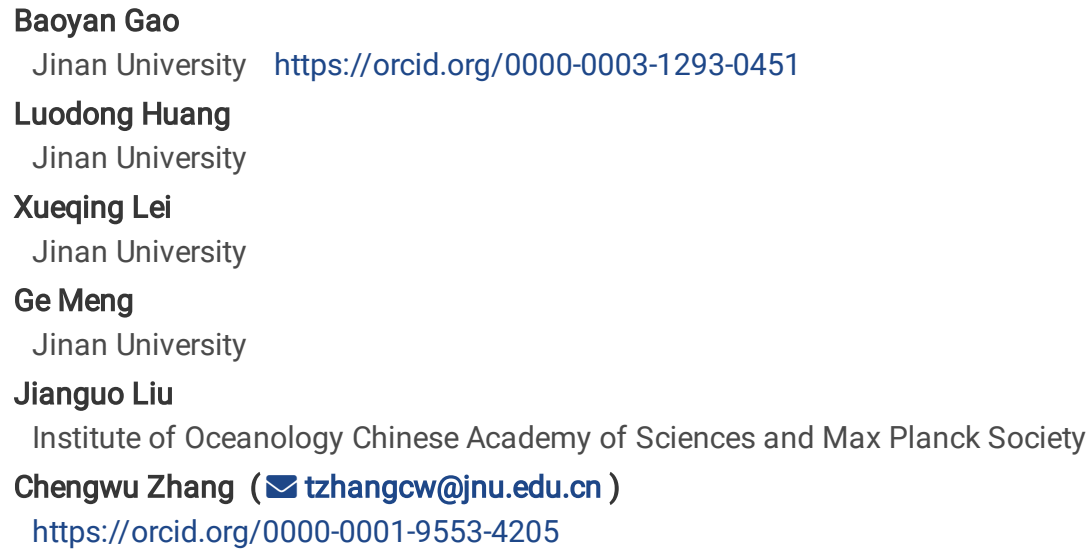

Research

Keywords: Lobosphaera bisecta, Lipid, Polyunsaturated fatty acid, Arachidonic acid, Transcriptome analysis

Posted Date: December 20th, 2019

DOI: https://doi.org/10.21203/rs.2.19487/v1

License: (c) (i) This work is licensed under a Creative Commons Attribution 4.0 International License. Read Full License 


\section{Abstract}

Background

Microalgae can synthesize and accumulate various components that can be used in health supplements, pharmaceuticals, cosmeceuticals, and other bioproducts. Arachidonic acid (AA) is an omega-6 long-chain polyunsaturated fatty acid and is important for human health. The coccoid green microalga Lobosphaera bisecta SAG2043 has been reported to be able to accumulate high AA content under certain conditions. We evaluated the interactive effects of nitrogen concentration, light intensity, and medium replacement on the growth and accumulation of lipids and $A A$ in this strain. We further performed transcriptome analysis on L. bisecta in order to elucidate the mechanism of AA and triacylglycerol (TAG) metabolism under nitrogen deficiency.

Results

Nutrient management and light intensity had significant effects on the biomass and accumulation of lipids and AA in L. bisecta. Both a high nitrogen concentration ( $18 \mathrm{mM}$ ) and high light intensity (bilateral light-300 $\mu \mathrm{mol} \mathrm{m}-2 \mathrm{~s}-1$ ) were beneficial to the growth of $L$. bisecta, and the replacement of culture medium further enhanced the biomass, which eventually reached $8.9 \mathrm{~g} \mathrm{~L}-1$. Low nitrogen concentration (3.6 mM) and high light significantly promoted the accumulation of lipids and AA. The highest lipid and AA content reached $54.0 \%$ and $10.8 \%$ of dry weight, respectively. Lipid compositions analysis under low nitrogen concentration showed that neutral lipids comprised $86.5 \%$ of the total lipids, and $88.2 \%$ of AA was distributed within the neutral lipids. We then reconstructed the lipid metabolic pathways of $L$. bisecta for the first time, and demonstrated that upregulation of a key desaturase and elongase in the $\Delta 6$ pathway was conducive to the accumulation of fatty acids toward AA synthesis. The synthesis of oleic acid, especially, ensured an adequate supply of precursor for AA synthesis. In addition, crucial genes within the TAG synthesis pathway were also up-regulated.

Conclusion

L. bisecta SAG2043 exhibits rapid growth, and high lipid and AA production. It may be a potential candidate for AA production. Transcriptome analysis showed that multi-level regulation ensured the conversion efficiency from carbon to the synthesis of fatty acids, which significantly promoted the accumulation of AA and TAG in L. bisecta.

\section{Background}

Arachidonic acid (AA) is an omega-6 ( $\omega-6), 20$ carbon-long chain polyunsaturated fatty acid (LC-PUFA) with four double bonds (5, 8, 11, 14eicosatetraenoic acid, C20:4). It is an integral constituent of biological cell membranes and one of the major polyunsaturated fatty acids (PUFAs) that constitute the brain membrane phospholipid [1]. It is also a precursor of the synthesis of eicosanoid hormones, such as prostaglandin, thromboxane, and leukotriene [2]. In addition, AA plays an important role in immune-suppressant, and induce inflammatory responses, blood clotting and cell signaling [1]. While, AA cannot be synthesized by humans and mammals, and it must be provided by exogenous sources, such as food supplement [3]. Thus, the demand for abundant, safe, and edible AA as a food ingredient is imperative. The primary sources of AA are porcine liver, adrenal glands, and fish oil, etc., but the content in these sources is rather low (about $0.2-0.5 \%$ ), and as such, alternative sources are being sought [4].

Microalgae can synthesize various components, including lipids, PUFAs, pigments, and other bioactive metabolites, which can be used in biofuels, health supplements, pharmaceuticals, and cosmeceuticals [5]. Many microalgae possess a certain amount of PUFAs, which are generally deposited in the polar lipids of cell membrane systems. The contents of PUFAs are very limited and strictly regulated [6]. Although oleaginous microalgae can accumulate a high content of neutral lipids, particularly triacylglycerols (TAGs), under stressful conditions such as high light and nitrogen deficiency, the fatty acid composition of TAGs are mostly saturated and monounsaturated fatty acids [6]. LC-PUFAs of the $\omega$-3 family, such as eicosapentaenoic acid (EPA) and docosahexaenoic acid (DHA), are rich in some microalgae, while $\omega$ - 6 LC-PUFAs are relatively rare [6, 7]. Microalgae that contain a relatively high content of AA are concentrated in several strains of Rhodophyta and Euglenoid, such as Pseudochantransia sp. SAG 19.96, Porphyridium cruentum SAG 1380-1e, Rhabdomonas incurva SAG 1271-8, and Khawkinea quartana SAG 1204-9, which the AA content was reported to be $68.3 \%, 44.5 \%, 41.3 \%$, and $34.3 \%$ of the total fatty acid, respectively [8]. It is worth noting that AA accumulation varied among different strains of the same species. Under the same culture condition, AA content was $44.5 \%$ in Porphyridium purpureum SAG 1380-1e, but only 3.8\% in SAG 1380-1d [8]. Gracilaria verrucosa was shown to be able to accumulate AA up to 45.9-62.0\% of the total fatty acids, but the total lipid content was very limited, only $0.27-1.52 \%$ of the dry weight [9]. In order to promote microalgal usage for the commercial production of PUFAs and LC-PUFA-rich oils, it is necessary to screen and select oleaginous microalgal species with the capacity to store LC-PUFA in TAGs, which would allow for more cost-effective production of PUFAs and oil. Therefore, it is urgent to find the species that can accumulate high AA levels in neutral lipids.

Lobosphaera incisa (syn. Parietochloris incisa, Myrmecia incisa), which belongs to Trebouxiphyceae, Chlorophyta, was first considered to be the richest plant source of AA. L. incisa was an oleaginous microalga that stored lipids rich in AA, and the AA content could reach $60 \%$ of the total 
fatty acid content [6]. Lobosphaera bisecta (formerly known as Myrmecia bisecta), which also belongs to Trebouxiphyceae and is a close relative of $\mathrm{L}$. incisa, has been shown to be able to accumulate high AA content, reaching more than $50 \%$ of the total fatty acid content under certain conditions $[8,10]$. However, there have been few studies on this microalga, and the information regarding lipid accumulation and fatty acid metabolism in this strain is limited. Therefore, in this study we aimed to comprehensively evaluate the effects of two different nitrogen concentrations, three different light intensities, and four different treatments of medium replacement on the biomass, lipid and AA accumulation in the L. bisecta. Furthermore, we performed transcriptome analysis of L. bisecta in order to elucidate AA and TAG metabolism under nitrogen deficiency.

\section{Results And Discussion}

2.1 Evaluation of oleaginous microalga L. bisecta SAG2043 for lipid and AA production

Environmental parameters, including light, temperature, and nutrient levels, strongly influences the growth and intracellular biochemical composition of microalgae [16]. Herein, we investigated the effect of two nitrogen concentrations, $18 \mathrm{mM}$ and $3.6 \mathrm{mM}$, represented as high and low nitrogen concentration, respectively, three light intensities (ul-100, ul-300, bl-300), and four medium replacement treatments (18 mM to $18 \mathrm{mM}, 18 \mathrm{mM}$ to $0 \mathrm{mM}, 3.6 \mathrm{mM}$ to $3.6 \mathrm{mM}, 3.6 \mathrm{mM}$ to $0 \mathrm{mM}$ ) on the growth, lipid content, and fatty acids profiles of L. bisecta SAG2043.

\subsubsection{Effects of different nitrogen concentrations, light intensity, and medium replacement on the growth of L. bisecta SAG2043}

Growth curves under different initial nitrogen concentrations and light intensities showed that the biomass of L. bisecta SAG2043 increased gradually with the culture time, but there were significant differences in the growth rate and total biomass concentration of different experimental groups (Fig. 1a). Under the condition of ul-100, the difference of biomass with two different nitrogen concentrations was relatively small, and the maximum biomass of high nitrogen and low nitrogen concentration was $3.8 \mathrm{~g} \mathrm{~L}^{-1}$ and $3.5 \mathrm{~g} \mathrm{~L}^{-1}$, respectively. Under the condition of ul-300, the growth rate was higher than that under the condition of low light intensity, and the maximum biomass with high and low nitrogen concentrations was $5.0 \mathrm{~g} \mathrm{~L}^{-1}$ and $4.5 \mathrm{~g} \mathrm{~L}^{-1}$, respectively. To further improve the light intensity, cool white fluorescent lamps were supplied on either side of the photobioreactor, which was bl-300. Under the condition of bl-300, the growth rate was much higher compared to the culture of unilateral illumination condition (ul-100, ul-300), and the growth rate with high and low nitrogen concentrations was slightly different. The maximum biomass was eventually $5.6 \mathrm{~g} \mathrm{~L}^{-1}(\mathrm{HN})$ and $5.1 \mathrm{~g} \mathrm{~L}^{-1}(\mathrm{LN})$. Microalgae are generally photosynthetic organism that need light as an energy source in order to convert carbon and water into biomass. Therefore, light intensity is one of the major limiting factors in microalgae growth, and it directly influences the biochemical composition and biomass of microalgae [5]. In our study, high light intensity promoted the growth of L. bisecta SAG2043 despite the culture being under high nitrogen or low nitrogen concentration. Actually, too high or too low light intensities were not beneficial to the growth of microalgae. Optimal light requirement for biomass accumulation varied between different microalgae [5]. For Euglena gracilis, the light intensity of $100 \mu \mathrm{mol} \mathrm{m} \mathrm{m}^{-2} \mathrm{~s}^{-1}$ was optimal, and the growth rate decreased over $150 \mu \mathrm{mol} \mathrm{m}^{-2} \mathrm{~s}^{-1}$ [17]. For L. bisecta SAG2043, bl-300 still had a positive effect on growth. Nitrogen is an essential element and macronutrient in microalgal cells, and plays an important role in growth, photosynthesis, and energy metabolism [18]. Nitrogen limitation in the culture can reduce the growth of microalgae. High nitrogen concentration was beneficial to the biomass accumulation of L. bisecta SAG2043, especially under high light intensity.

Under the bl-300, the growth rate was decreased after 9 days of cultivation. In order to sustain long-term cell growth, we replaced the supernatant of the culture with fresh medium at this time point ( 9 days) (Fig. 1b). After the four different treatments of medium replacement, the maximum biomass was eventually reached, which was $8.9 \mathrm{~g} \mathrm{~L}^{-1}(18 \mathrm{mM}$ to $18 \mathrm{mM}, \mathrm{HN}-\mathrm{HN}), 8.3 \mathrm{~g} \mathrm{~L}^{-1}$ (18 mM to $\left.0 \mathrm{mM}, \mathrm{HN}-\mathrm{NN}\right), 8.6 \mathrm{~g} \mathrm{~L}-1$ (3.6 mM to $3.6 \mathrm{mM}, \mathrm{LN}-\mathrm{LN})$ and $7.6 \mathrm{~g} \mathrm{~L}^{-1}(3.6 \mathrm{mM}$ to $0 \mathrm{mM}, \mathrm{LN}-\mathrm{NN})$. Obviously, replacement of culture medium significantly enhanced the biomass accumulation of L. bisecta SAG2043. The biomass under fresh medium containing a high or low nitrogen supply (HN-HN, LN-LN) was higher than that of fresh medium without a nitrogen supply (HN-NF, LN-NF). This indicated that the decrease in the growth rate was mainly due to nutrient deficiency, especially nitrogen. This result was also observed in other studies about replacement cultivation [19, 20, 21]. Replacement with fresh medium not only supplied nutrients to promote the growth of L. bisecta SAG2043, but also removed the extracellular metabolites in the old medium, which may inhibit the cell growth or induce cell death produced in old medium [20].

\subsubsection{Effects of different nitrogen concentrations, light intensity and medium replacement on the lipid content of L. bisecta SAG2043}

During the course of culture, the lipid content of L. bisecta SAG2043 increased gradually (Fig. 2a). Under the same nitrogen concentration, the lipid content under a high light condition was higher than it was under a low light intensity. Under the same light intensity, the lipid content at a low nitrogen concentration was higher than that observed under a high nitrogen concentration. Under ul-100, the maximum lipid content accounted for $29.3 \%(18 \mathrm{mM})$ and $34.0 \%(3.6 \mathrm{mM})$ of the dry weight on the last day of the culture. Under the condition of ul-300, the lipid accumulation rate was faster than it was under low light, and the maximum lipid content reached $40.4 \%$ (18 $\mathrm{mM})$ and $43.2 \%(3.6 \mathrm{mM})$ of the dry weight. Under bl-300, the lipid content under high and low nitrogen concentrations reached the maximum on the last day of the culture, accounting for $42.1 \%(18 \mathrm{mM})$ and $46.5 \%(3.6 \mathrm{mM})$ of the dry weight, respectively. Light intensity and nitrogen concentration were important 
factors influencing the lipid content in the cells of L. bisecta SAG2043. In our study, high light intensity and low nitrogen concentration were conducive to lipid accumulation in L. bisecta SAG2043. In most algae, lipid metabolism was regulated by environmental variables [22]. Various studies have been conducted to investigate the effect of environment parameters and key nutrients on the lipid biosynthesis of microalgae, and the method of bioprocess engineering was the simplest, and most effective strategy used to trigger lipid accumulation in microalgae [23]. The lack of nutrients caused unfavorable situations, and the cells enhanced lipid accumulation as a response. A positive correlation between the lipid content and culture time was revealed during the comparison of lipid content in the exponential and stationary growth phase of L. bisecta SAG2043. As culture time prolonged, nitrogen in the culture medium was consumed, and intracellular nitrogen decreased. Thus, cells in stationary phase are under more nitrogen stress than those in exponential phase. This is consistent with what was reported in other studies [24, 25]. However, several strains of Tetraselmis were shown to produce more lipids during exponential growth than in the stationary growth [26]. Light intensity is an important parameter that influences the lipid content of microalgae [22]. Many studies have been performed to show that high light intensity is needed in order to obtain higher lipid accumulation. Liu et al. reported that lipid content in Scenedesmus sp. was increased 11 -fold when the light intensity was changed from 250 to $400 \mu \mathrm{mol}$ photons $\mathrm{m}^{-2} \mathrm{~s}^{-1}$ [27]. Takeshita et al. [28] showed that eight strains of Chlorella accumulated more lipids with a high light intensity of $600 \mu \mathrm{mol}$ photons $\mathrm{m}^{-2} \mathrm{~s}^{-1}$. In the culture system of this experiment, the maximum light intensity achieved was $300 \mu \mathrm{mol}$ photons $\mathrm{m}^{-2} \mathrm{~s}^{-1}$, and we further increased the light intensity by putting cool white fluorescent lamps on either side of the photobioreactor, which was bl-300. This method added the ratio between light exposure surface area and volume of culture.

The change of total lipid content in the L. bisecta SAG2043 under four treatments of medium replacement (HN-HN, HN-NF, LN-LN, LN-NF) is shown in Fig. 2b. The lipid content in the cells reached more than $30 \%$ of the dry weight on the day 9 . After the replacement of medium, the lipid content in the nitrogen-replete experimental group $(\mathrm{HN}-\mathrm{HN}, \mathrm{LN}-\mathrm{LN})$ first decreased and then increased. The lipid content in the nitrogen-free group (HN-NF, LN-NF) increased gradually during the entire culture period. The lipid content under the four treatments of replacement cultivation reached the maximum on the last day of culture, which were $36.7 \%(\mathrm{HN}-\mathrm{HN}), 40.1 \%(\mathrm{HN}-\mathrm{NF}), 45.8 \%$ (LN-LN) and $54.0 \%$ (LN-NF) of dry weight, respectively. The duration of nitrogen deprivation was also an important factor that influenced the lipid accumulation [23]. Under prolonged nitrogen stress, lipid synthesis continued and lipid content was much higher in the fresh medium without nitrogen than it was obtained under shorter culture time. Nitrogen-replete conditions decreased the lipid content in L. bisecta SAG2043. In contrast, it is unusual that nitrogen-replete condition resulted in lipid accumulation in Isochrysis zhangjiangensis [29]. This demonstrates that microalgae species exhibit different physiological behaviors under nitrogen stress.

2.1.3 Effects of different nitrogen concentrations, light intensity, and medium replacement on the fatty acids profile of L. bisecta SAG2043

In addition to the lipid content, a high quality of fatty acids profile is also crucial in biodiesel production and nutraceutical applications. The main fatty acids of L. bisecta SAG2043 were palmitic acid (C16:0), stearic acid (C18:0), oleic acid (C18:1), linoleic acid (C18:2), linolenic acid (C18:3), arachidonic acid (AA, C20:4), and eicosapentaenoic acid (EPA, C20:5). Under different light intensities (Table 1, Table 2, Table 3), the change in the relative content of main fatty acids (\% total fatty acids) under two nitrogen concentrations were similar. The content of $\mathrm{C} 16: 0$, C18:0, C18:2 and C20:5 was decreased with the culture time, while the content of C18:1 and C20:4 was increased. Interesting, when the AA content in L. bisecta SAG2043 reached $24-26 \%$ of total fatty acid, the relative content of AA held steady with the culture time and nitrogen concentration (Table 2). Compared to culture in a high nitrogen concentration $(18 \mathrm{mM})$ and low light intensity $\left(100 \mu \mathrm{mol} \mathrm{m}^{-2} \mathrm{~s}^{-1}\right)$, the change in the individual fatty acid content in the culture grown under a low nitrogen concentration (3.6 mM) and high light intensity $\left(300 \mu \mathrm{mol} \mathrm{m}^{-2} \mathrm{~s}^{-1}\right.$; bilateral illumination) was even more pronounced. In general, nitrogen deficiency and high light increased the saturation level of algal fatty acids [23]. In L. bisecta SAG2043, the content of saturated fatty acids (SFA) and PUFAs was decreased, whereas monounsaturated fatty acids (MUFA), which was oleic acid (C18:1) in L. bisecta SAG2043, was increased with culture time. Oleic acid was the most abundant fatty acid produced during stationary growth phase. This is a common phenomenon in green algae [30]. However, this fatty acid composition in L. bisecta SAG2043 differed distinctly from that in the L. incisa K-1 and L. incisa SAG 2468, which contained a relative low proportion of oleic acid [31]. Breuer et al. [30] also reported that the ratio of valuable PUFAs, EPA, AA, and DHA to the total fatty acids in Phaeodactylum tricornutum, Porphyridium cruentum, and Isochrysis galbana decreased in nitrogen-deficient culture. Whereas, AA content in L. bisecta SAG 2043 was increased gradually until it reached to $26 \%$ of the total fatty acid. The change trend of the relative content of main fatty acids (\% total fatty acids) for the four treatments of medium replacement was similar to the condition without medium replacement (Table 4, Table 5). 
Table 1

Change in the fatty acid content of L. bisecta SAG2043 with two nitrogen concentrations (18 mM, 3.6 mM) under unilateral low light intensity (ul100) over a time course

\begin{tabular}{|c|c|c|c|c|c|c|c|c|c|c|}
\hline \multirow[b]{2}{*}{ day } & \multicolumn{5}{|c|}{$\mathrm{ul}-100+18 \mathrm{mM}$} & \multicolumn{5}{|c|}{$\mathrm{ul}-100+3.6 \mathrm{mM}$} \\
\hline & 3 & 6 & 9 & 12 & 15 & 3 & 6 & 9 & 12 & 15 \\
\hline C16:0 & $\begin{array}{l}13.24 \pm \\
1.34\end{array}$ & $\begin{array}{l}12.10 \pm \\
0.97\end{array}$ & $\begin{array}{l}12.30 \pm \\
1.25\end{array}$ & $\begin{array}{l}11.26 \pm \\
1.76\end{array}$ & $\begin{array}{l}11.40 \pm \\
1.57\end{array}$ & $\begin{array}{l}14.38 \pm \\
1.16\end{array}$ & $\begin{array}{l}13.10 \pm \\
0.68\end{array}$ & $\begin{array}{l}11.30 \pm \\
0.82\end{array}$ & $\begin{array}{l}11.00 \pm \\
0.76\end{array}$ & $\begin{array}{l}9.51 \pm \\
1.52\end{array}$ \\
\hline C18:0 & $\begin{array}{l}2.90 \pm \\
0.26\end{array}$ & $\begin{array}{l}3.12 \pm \\
0.20\end{array}$ & $\begin{array}{l}2.56 \pm \\
0.34\end{array}$ & $\begin{array}{l}1.28 \pm \\
0.42\end{array}$ & $\begin{array}{l}2.27 \pm \\
0.55\end{array}$ & $\begin{array}{l}3.09 \pm \\
0.14\end{array}$ & $\begin{array}{l}2.56 \pm \\
0.37\end{array}$ & $\begin{array}{l}1.56 \pm \\
0.14\end{array}$ & $\begin{array}{l}1.28 \pm \\
0.40\end{array}$ & $\begin{array}{l}0.85 \pm \\
0.21\end{array}$ \\
\hline C18:1 & $\begin{array}{l}14.44 \pm \\
1.32\end{array}$ & $\begin{array}{l}22.87 \pm \\
1.49\end{array}$ & $\begin{array}{l}26.30 \pm \\
1.46\end{array}$ & $\begin{array}{l}31.78 \pm \\
1.50\end{array}$ & $\begin{array}{l}33.82 \pm \\
1.64\end{array}$ & $\begin{array}{l}17.90 \pm \\
1.27\end{array}$ & $\begin{array}{l}24.67 \pm \\
1.33\end{array}$ & $\begin{array}{l}33.73 \pm \\
1.39\end{array}$ & $\begin{array}{l}36.78 \pm \\
1.47\end{array}$ & $\begin{array}{l}41.64 \pm \\
1.82\end{array}$ \\
\hline C18:2 & $\begin{array}{l}21.38 \pm \\
1.03\end{array}$ & $\begin{array}{l}19.62 \pm \\
1.22\end{array}$ & $\begin{array}{l}19.48 \pm \\
1.00\end{array}$ & $\begin{array}{l}17.40 \pm \\
1.17\end{array}$ & $\begin{array}{l}18.59 \pm \\
1.35\end{array}$ & $\begin{array}{l}20.05 \pm \\
1.44\end{array}$ & $\begin{array}{l}19.62 \pm \\
1.60\end{array}$ & $\begin{array}{l}19.48 \pm \\
1.85\end{array}$ & $\begin{array}{l}17.04 \pm \\
1.08\end{array}$ & $\begin{array}{l}15.90 \pm \\
1.37\end{array}$ \\
\hline C18:3 & $\begin{array}{l}7.44 \pm \\
0.51\end{array}$ & $\begin{array}{l}8.51 \pm \\
0.64\end{array}$ & $\begin{array}{l}4.37 \pm \\
0.41\end{array}$ & $\begin{array}{l}4.66 \pm \\
0.38\end{array}$ & $\begin{array}{l}3.50 \pm \\
0.42\end{array}$ & $\begin{array}{l}10.13 \pm \\
0.62\end{array}$ & $\begin{array}{l}8.51 \pm \\
0.63\end{array}$ & $\begin{array}{l}4.37 \pm \\
0.47\end{array}$ & $\begin{array}{l}4.66 \pm \\
0.19\end{array}$ & $\begin{array}{l}2.99 \pm \\
0.14\end{array}$ \\
\hline C20:4 & $\begin{array}{l}19.21 \pm \\
0.92\end{array}$ & $\begin{array}{l}23.58 \pm \\
0.65\end{array}$ & $\begin{array}{l}24.30 \pm \\
0.48\end{array}$ & $\begin{array}{l}24.69 \pm \\
1.28\end{array}$ & $\begin{array}{l}24.24 \pm \\
1.32\end{array}$ & $\begin{array}{l}25.74 \pm \\
0.83\end{array}$ & $\begin{array}{l}23.58 \pm \\
1.22\end{array}$ & $\begin{array}{l}24.30 \pm \\
0.91\end{array}$ & $\begin{array}{l}24.69 \pm \\
1.11\end{array}$ & $\begin{array}{l}22.89 \pm \\
1.08\end{array}$ \\
\hline C20:5 & $\begin{array}{l}2.27 \pm \\
0.52\end{array}$ & $\begin{array}{l}2.78 \pm \\
0.33\end{array}$ & $\begin{array}{l}2.11 \pm \\
0.41\end{array}$ & $\begin{array}{l}2.21 \pm \\
0.18\end{array}$ & $\begin{array}{l}1.49 \pm \\
0.65\end{array}$ & $\begin{array}{l}3.08 \pm \\
0.59\end{array}$ & $\begin{array}{l}2.78 \pm \\
0.81\end{array}$ & $\begin{array}{l}2.11 \pm \\
0.55\end{array}$ & $\begin{array}{l}2.21 \pm \\
0.72\end{array}$ & $\begin{array}{l}1.71 \pm \\
0.50\end{array}$ \\
\hline SFA & $\begin{array}{l}16.14 \pm \\
1.13\end{array}$ & $\begin{array}{l}15.22 \pm \\
1.51\end{array}$ & $\begin{array}{l}14.86 \pm \\
0.84\end{array}$ & $\begin{array}{l}12.54 \pm \\
1.44\end{array}$ & $\begin{array}{l}13.67 \pm \\
1.53\end{array}$ & $\begin{array}{l}17.47 \pm \\
1.64\end{array}$ & $\begin{array}{l}15.66 \pm \\
1.62\end{array}$ & $\begin{array}{l}12.86 \pm \\
1.39\end{array}$ & $\begin{array}{l}12.28 \pm \\
1.22\end{array}$ & $\begin{array}{l}10.36 \pm \\
1.43\end{array}$ \\
\hline PUFA & $\begin{array}{l}50.30 \pm \\
2.31\end{array}$ & $\begin{array}{l}54.49 \pm \\
1.87\end{array}$ & $\begin{array}{l}50.26 \pm \\
2.65\end{array}$ & $\begin{array}{l}48.60 \pm \\
2.47\end{array}$ & $\begin{array}{l}47.82 \pm \\
2.33\end{array}$ & $\begin{array}{l}59.00 \pm \\
2.53\end{array}$ & $\begin{array}{l}54.49 \pm \\
0.95\end{array}$ & $\begin{array}{l}50.26 \pm \\
2.96\end{array}$ & $\begin{array}{l}48.60 \pm \\
2.41\end{array}$ & $\begin{array}{l}43.49 \pm \\
1.64\end{array}$ \\
\hline
\end{tabular}

Table 2

Change in the fatty acid content of L. bisecta SAG2043 with two nitrogen concentrations (18 mM, $3.6 \mathrm{mM})$ under unilateral high light intensity (ul-300) over a time course

\begin{tabular}{|c|c|c|c|c|c|c|c|c|c|c|}
\hline \multirow[b]{2}{*}{ day } & \multicolumn{5}{|c|}{$\mathrm{ul}-300+18 \mathrm{mM}$} & \multicolumn{5}{|c|}{ ul-300 + $3.6 \mathrm{mM}$} \\
\hline & 3 & 6 & 9 & 12 & 15 & 3 & 6 & 9 & 12 & 15 \\
\hline C16:0 & $\begin{array}{l}13.14 \pm \\
1.12\end{array}$ & $\begin{array}{l}13.56 \pm \\
0.85\end{array}$ & $\begin{array}{l}11.81 \pm \\
1.03\end{array}$ & $\begin{array}{l}10.67 \pm \\
0.59\end{array}$ & $\begin{array}{l}10.23 \pm \\
0.67\end{array}$ & $\begin{array}{l}13.53 \pm \\
1.40\end{array}$ & $\begin{array}{l}11.19 \pm \\
0.69\end{array}$ & $\begin{array}{l}10.24 \pm \\
0.85\end{array}$ & $\begin{array}{l}9.41 \pm \\
0.70\end{array}$ & $\begin{array}{l}9.14 \pm \\
0.68\end{array}$ \\
\hline C18:0 & $\begin{array}{l}2.59 \pm \\
0.52\end{array}$ & $\begin{array}{l}2.90 \pm \\
0.46\end{array}$ & $\begin{array}{l}2.25 \pm \\
0.56\end{array}$ & $\begin{array}{l}1.71 \pm \\
0.62\end{array}$ & $\begin{array}{l}1.46 \pm \\
0.34\end{array}$ & $\begin{array}{l}2.81 \pm \\
0.45\end{array}$ & $\begin{array}{l}1.51 \pm \\
0.48\end{array}$ & $\begin{array}{l}0.98 \pm \\
0.28\end{array}$ & $\begin{array}{l}0.77 \pm \\
0.55\end{array}$ & $\begin{array}{l}0.61 \pm \\
0.49\end{array}$ \\
\hline C18:1 & $\begin{array}{l}19.35 \pm \\
1.33\end{array}$ & $\begin{array}{l}24.11 \pm \\
1.28\end{array}$ & $\begin{array}{l}31.31 \pm \\
1.50\end{array}$ & $\begin{array}{l}37.29 \pm \\
0.85\end{array}$ & $\begin{array}{l}39.65 \pm \\
1.34\end{array}$ & $\begin{array}{l}19.44 \pm \\
1.55\end{array}$ & $\begin{array}{l}29.89 \pm \\
1.08\end{array}$ & $\begin{array}{l}37.94 \pm \\
0.98\end{array}$ & $\begin{array}{l}39.99 \pm \\
1.27\end{array}$ & $\begin{array}{l}40.52 \pm \\
1.54\end{array}$ \\
\hline C18:2 & $\begin{array}{l}17.15 \pm \\
1.08\end{array}$ & $\begin{array}{l}18.52 \pm \\
1.22\end{array}$ & $\begin{array}{l}17.20 \pm \\
1.46\end{array}$ & $\begin{array}{l}14.68 \pm \\
1.38\end{array}$ & $\begin{array}{l}14.27 \pm \\
1.27\end{array}$ & $\begin{array}{l}15.72 \pm \\
1.54\end{array}$ & $\begin{array}{l}14.75 \pm \\
0.82\end{array}$ & $\begin{array}{l}13.21 \pm \\
0.55\end{array}$ & $\begin{array}{l}12.88 \pm \\
1.16\end{array}$ & $\begin{array}{l}13.13 \pm \\
0.86\end{array}$ \\
\hline C18:3 & $\begin{array}{l}8.50 \pm \\
0.54\end{array}$ & $\begin{array}{l}6.50 \pm \\
0.56\end{array}$ & $\begin{array}{l}4.46 \pm \\
0.48\end{array}$ & $\begin{array}{l}3.65 \pm \\
0.44\end{array}$ & $\begin{array}{l}3.24 \pm \\
0.52\end{array}$ & $\begin{array}{l}7.96 \pm \\
0.81\end{array}$ & $\begin{array}{l}5.11 \pm \\
0.60\end{array}$ & $\begin{array}{l}4.21 \pm \\
0.54\end{array}$ & $\begin{array}{l}3.81 \pm \\
0.34\end{array}$ & $\begin{array}{l}3.59 \pm \\
0.28\end{array}$ \\
\hline C20:4 & $\begin{array}{l}24.26 \pm \\
1.41\end{array}$ & $\begin{array}{l}23.32 \pm \\
1.18\end{array}$ & $\begin{array}{l}23.91 \pm \\
2.21\end{array}$ & $\begin{array}{l}23.68 \pm \\
0.71\end{array}$ & $\begin{array}{l}24.08 \pm \\
1.79\end{array}$ & $\begin{array}{l}26.29 \pm \\
1.05\end{array}$ & $\begin{array}{l}26.29 \pm \\
1.91\end{array}$ & $\begin{array}{l}26.00 \pm \\
1.52\end{array}$ & $\begin{array}{l}26.16 \pm \\
0.84\end{array}$ & $\begin{array}{l}26.57 \pm \\
0.79\end{array}$ \\
\hline C20:5 & $\begin{array}{l}2.68 \pm \\
0.84\end{array}$ & $\begin{array}{l}2.37 \pm \\
0.42\end{array}$ & $\begin{array}{l}1.89 \pm \\
0.10\end{array}$ & $\begin{array}{l}1.63 \pm \\
0.32\end{array}$ & $\begin{array}{l}1.50 \pm \\
0.33\end{array}$ & $\begin{array}{l}2.94 \pm \\
0.65\end{array}$ & $\begin{array}{l}2.29 \pm \\
0.63\end{array}$ & $\begin{array}{l}1.83 \pm \\
0.39\end{array}$ & $\begin{array}{l}1.68 \pm \\
0.37\end{array}$ & $\begin{array}{l}1.69 \pm \\
0.48\end{array}$ \\
\hline SFA & $\begin{array}{l}15.73 \pm \\
1.42\end{array}$ & $\begin{array}{l}16.46 \pm \\
1.36\end{array}$ & $\begin{array}{l}14.06 \pm \\
1.58\end{array}$ & $\begin{array}{l}12.38 \pm \\
0.77\end{array}$ & $\begin{array}{l}11.69 \pm \\
1.07\end{array}$ & $\begin{array}{l}16.34 \pm \\
0.91\end{array}$ & $\begin{array}{l}12.70 \pm \\
1.55\end{array}$ & $\begin{array}{l}11.22 \pm \\
1.37\end{array}$ & $\begin{array}{l}10.18 \pm \\
1.25\end{array}$ & $\begin{array}{l}9.75 \pm \\
1.02\end{array}$ \\
\hline PUFA & $\begin{array}{l}52.59 \pm \\
2.76\end{array}$ & $\begin{array}{l}50.71 \pm \\
3.01\end{array}$ & $\begin{array}{l}47.46 \pm \\
2.33\end{array}$ & $\begin{array}{l}43.64 \pm \\
1.84\end{array}$ & $\begin{array}{l}43.09 \pm \\
2.38\end{array}$ & $\begin{array}{l}52.91 \pm \\
1.75\end{array}$ & $\begin{array}{l}49.06 \pm \\
2.67\end{array}$ & $\begin{array}{l}45.25 \pm \\
1.41\end{array}$ & $\begin{array}{l}44.53 \pm \\
2.51\end{array}$ & $\begin{array}{l}44.98 \pm \\
2.97\end{array}$ \\
\hline
\end{tabular}


Table 3

Change in the fatty acid content of L. bisecta SAG2043 with two nitrogen concentrations (18 mM, 3.6 mM) under bilateral high light intensity (bI300) over a time course

\begin{tabular}{|c|c|c|c|c|c|c|c|c|c|c|}
\hline \multirow[b]{2}{*}{ day } & \multicolumn{5}{|c|}{ bl-300 + 18 mM } & \multicolumn{5}{|c|}{ bl-300 + 3.6 mM } \\
\hline & 3 & 6 & 9 & 12 & 15 & 3 & 6 & 9 & 12 & 15 \\
\hline C16:0 & $\begin{array}{l}18.43 \pm \\
1.26\end{array}$ & $\begin{array}{l}14.87 \pm \\
1.45\end{array}$ & $\begin{array}{l}11.31 \pm \\
0.80\end{array}$ & $\begin{array}{l}9.73 \pm \\
0.71\end{array}$ & $\begin{array}{l}9.02 \pm \\
0.98\end{array}$ & $\begin{array}{l}17.28 \pm \\
1.48\end{array}$ & $\begin{array}{l}14.27 \pm \\
1.20\end{array}$ & $\begin{array}{l}11.13 \pm \\
0.48\end{array}$ & $\begin{array}{l}10.26 \pm \\
1.01\end{array}$ & $\begin{array}{l}10.05 \pm \\
0.88\end{array}$ \\
\hline C18:0 & $\begin{array}{l}0.73 \pm \\
0.21\end{array}$ & $\begin{array}{l}1.05 \pm \\
0.42\end{array}$ & $\begin{array}{l}2.01 \pm \\
0.50\end{array}$ & $\begin{array}{l}1.51 \pm \\
0.35\end{array}$ & $\begin{array}{l}0.28 \pm \\
0.10\end{array}$ & $\begin{array}{l}0.64 \pm \\
0.22\end{array}$ & $\begin{array}{l}1.34 \pm \\
0.34\end{array}$ & $\begin{array}{l}1.24 \pm \\
0.66\end{array}$ & $\begin{array}{l}2.15 \pm \\
0.46\end{array}$ & $\begin{array}{l}2.22 \pm \\
0.68\end{array}$ \\
\hline C18:1 & $\begin{array}{l}21.30 \pm \\
1.10\end{array}$ & $\begin{array}{l}22.29 \pm \\
1.43\end{array}$ & $\begin{array}{l}37.19 \pm \\
1.68\end{array}$ & $\begin{array}{l}40.96 \pm \\
1.89\end{array}$ & $\begin{array}{l}41.45 \pm \\
2.04\end{array}$ & $\begin{array}{l}17.14 \pm \\
1.22\end{array}$ & $\begin{array}{l}32.86 \pm \\
1.35\end{array}$ & $\begin{array}{l}31.24 \pm \\
1.66\end{array}$ & $\begin{array}{l}42.25 \pm \\
2.53\end{array}$ & $\begin{array}{l}42.29 \pm \\
2.07\end{array}$ \\
\hline C18:2 & $\begin{array}{l}15.73 \pm \\
1.01\end{array}$ & $\begin{array}{l}17.46 \pm \\
1.15\end{array}$ & $\begin{array}{l}12.44 \pm \\
0.47\end{array}$ & $\begin{array}{l}13.86 \pm \\
1.06\end{array}$ & $\begin{array}{l}13.43 \pm \\
0.67\end{array}$ & $\begin{array}{l}18.85 \pm \\
1.47\end{array}$ & $\begin{array}{l}15.58 \pm \\
1.51\end{array}$ & $\begin{array}{l}14.86 \pm \\
1.03\end{array}$ & $\begin{array}{l}12.56 \pm \\
1.08\end{array}$ & $\begin{array}{l}12.99 \pm \\
0.84\end{array}$ \\
\hline C18:3 & $\begin{array}{l}8.71 \pm \\
0.64\end{array}$ & $\begin{array}{l}2.42 \pm \\
0.17\end{array}$ & $\begin{array}{l}2.21 \pm \\
0.50\end{array}$ & $\begin{array}{l}1.87 \pm \\
0.32\end{array}$ & $\begin{array}{l}1.56 \pm \\
0.41\end{array}$ & $\begin{array}{l}10.58 \pm \\
0.88\end{array}$ & $\begin{array}{l}1.19 \pm \\
0.49\end{array}$ & $\begin{array}{l}2.53 \pm \\
1.10\end{array}$ & $\begin{array}{l}1.79 \pm \\
0.67\end{array}$ & $\begin{array}{l}1.61 \pm \\
0.42\end{array}$ \\
\hline C20:4 & $\begin{array}{l}17.26 \pm \\
0.85\end{array}$ & $\begin{array}{l}20.21 \pm \\
1.18\end{array}$ & $\begin{array}{l}21.36 \pm \\
1.74\end{array}$ & $\begin{array}{l}22.67 \pm \\
2.01\end{array}$ & $\begin{array}{l}25.02 \pm \\
1.53\end{array}$ & $\begin{array}{l}14.72 \pm \\
1.11\end{array}$ & $\begin{array}{l}21.02 \pm \\
0.85\end{array}$ & $\begin{array}{l}22.28 \pm \\
2.07\end{array}$ & $\begin{array}{l}23.88 \pm \\
1.56\end{array}$ & $\begin{array}{l}24.93 \pm \\
1.37\end{array}$ \\
\hline C20:5 & $\begin{array}{l}2.91 \pm \\
0.48\end{array}$ & $\begin{array}{l}2.26 \pm \\
0.51\end{array}$ & $\begin{array}{l}1.61 \pm \\
0.62\end{array}$ & $\begin{array}{l}1.33 \pm \\
0.47\end{array}$ & $\begin{array}{l}1.14 \pm \\
0.13\end{array}$ & $\begin{array}{l}2.13 \pm \\
0.41\end{array}$ & $\begin{array}{l}2.71 \pm \\
0.58\end{array}$ & $\begin{array}{l}1.65 \pm \\
0.36\end{array}$ & $\begin{array}{l}1.45 \pm \\
0.39\end{array}$ & $\begin{array}{l}1.36 \pm \\
0.42\end{array}$ \\
\hline SFA & $\begin{array}{l}19.16 \pm \\
1.08\end{array}$ & $\begin{array}{l}15.92 \pm \\
1.27\end{array}$ & $\begin{array}{l}13.32 \pm \\
1.43\end{array}$ & $\begin{array}{l}11.24 \pm \\
1.60\end{array}$ & $\begin{array}{l}9.30 \pm \\
0.84\end{array}$ & $\begin{array}{l}17.92 \pm \\
1.51\end{array}$ & $\begin{array}{l}15.61 \pm \\
1.25\end{array}$ & $\begin{array}{l}12.37 \pm \\
1.02\end{array}$ & $\begin{array}{l}12.41 \pm \\
0.86\end{array}$ & $\begin{array}{l}12.27 \pm \\
0.51\end{array}$ \\
\hline PUFA & $\begin{array}{l}44.61 \pm \\
2.33\end{array}$ & $\begin{array}{l}42.35 \pm \\
1.54\end{array}$ & $\begin{array}{l}37.62 \pm \\
1.82\end{array}$ & $\begin{array}{l}39.73 \pm \\
1.07\end{array}$ & $\begin{array}{l}41.15 \pm \\
2.38\end{array}$ & $\begin{array}{l}46.28 \pm \\
2.64\end{array}$ & $\begin{array}{l}40.50 \pm \\
1.60\end{array}$ & $\begin{array}{l}41.32 \pm \\
2.27\end{array}$ & $\begin{array}{l}39.68 \pm \\
1.62\end{array}$ & $\begin{array}{l}40.89 \pm \\
2.68\end{array}$ \\
\hline
\end{tabular}

Table 4

Change in fatty acid content of L. bisecta SAG2043 with a high concentration of nitrogen (18 mM) under medium replacement cultivation over a time course. $18 \mathrm{mM}-18 \mathrm{mM}$, medium replacement from initial nitrogen concentration of $18 \mathrm{mM}$ to fresh medium of $18 \mathrm{mM}$ on day 9 ; $18 \mathrm{mM}$ $0 \mathrm{mM}$, medium replacement from initial nitrogen concentration of $18 \mathrm{mM}$ to fresh medium of $0 \mathrm{mM}$ on day 9

\begin{tabular}{|c|c|c|c|c|c|c|c|c|c|c|c|c|c|}
\hline \multirow[b]{2}{*}{ day } & \multicolumn{8}{|c|}{$18 \mathrm{mM}-18 \mathrm{mM}$} & \multicolumn{5}{|c|}{$18 \mathrm{mM}-0 \mathrm{mM}$} \\
\hline & 3 & 6 & 9 & 12 & 15 & 18 & 21 & 24 & 12 & 15 & 18 & 21 & 24 \\
\hline C16:0 & $\begin{array}{l}14.68 \pm \\
1.45\end{array}$ & $\begin{array}{l}14.37 \pm \\
1.33\end{array}$ & $\begin{array}{l}12.69 \pm \\
1.49\end{array}$ & $\begin{array}{l}12.96 \pm \\
0.82\end{array}$ & $\begin{array}{l}12.07 \pm \\
0.55\end{array}$ & $\begin{array}{l}11.11 \pm \\
1.20\end{array}$ & $\begin{array}{l}10.60 \pm \\
0.47\end{array}$ & $\begin{array}{l}10.28 \pm \\
0.82\end{array}$ & $\begin{array}{l}11.41 \pm \\
0.66\end{array}$ & $\begin{array}{l}10.06 \pm \\
0.38\end{array}$ & $\begin{array}{l}9.68 \pm \\
1.17\end{array}$ & $\begin{array}{l}9.40 \pm \\
1.37\end{array}$ & $\begin{array}{l}9.14 \pm \\
0.92\end{array}$ \\
\hline C18:0 & $\begin{array}{l}0.27 \pm \\
0.10\end{array}$ & $\begin{array}{l}0.74 \pm \\
0.48\end{array}$ & $\begin{array}{l}1.22 \pm \\
0.38\end{array}$ & $\begin{array}{l}0.89 \pm \\
0.25\end{array}$ & $\begin{array}{l}1.15 \pm \\
0.11\end{array}$ & $\begin{array}{l}1.30 \pm \\
0.41\end{array}$ & $\begin{array}{l}1.44 \pm \\
0.42\end{array}$ & $\begin{array}{l}1.46 \pm \\
0.55\end{array}$ & $\begin{array}{l}1.38 \pm \\
0.69\end{array}$ & $\begin{array}{l}1.80 \pm \\
0.81\end{array}$ & $\begin{array}{l}2.02 \pm \\
0.72\end{array}$ & $\begin{array}{l}2.14 \pm \\
0.84\end{array}$ & $\begin{array}{l}2.11 \pm \\
0.66\end{array}$ \\
\hline C18:1 & $\begin{array}{l}15.23 \pm \\
1.17\end{array}$ & $\begin{array}{l}19.35 \pm \\
1.24\end{array}$ & $\begin{array}{l}25.02 \pm \\
2.21\end{array}$ & $\begin{array}{l}22.85 \pm \\
1.48\end{array}$ & $\begin{array}{l}28.80 \pm \\
1.34\end{array}$ & $\begin{array}{l}33.65 \pm \\
2.50\end{array}$ & $\begin{array}{l}36.11 \pm \\
2.03\end{array}$ & $\begin{array}{l}37.32 \pm \\
2.21\end{array}$ & $\begin{array}{l}32.59 \pm \\
1.67\end{array}$ & $\begin{array}{l}36.26 \pm \\
1.77\end{array}$ & $\begin{array}{l}38.74 \pm \\
2.24\end{array}$ & $\begin{array}{l}39.38 \pm \\
2.35\end{array}$ & $\begin{array}{l}39.65 \pm \\
2.49\end{array}$ \\
\hline C18:2 & $\begin{array}{l}13.25 \pm \\
1.24\end{array}$ & $\begin{array}{l}18.14 \pm \\
0.79\end{array}$ & $\begin{array}{l}16.82 \pm \\
1.90\end{array}$ & $\begin{array}{l}18.92 \pm \\
1.13\end{array}$ & $\begin{array}{l}17.33 \pm \\
1.48\end{array}$ & $\begin{array}{l}16.23 \pm \\
1.67\end{array}$ & $\begin{array}{l}15.27 \pm \\
1.24\end{array}$ & $\begin{array}{l}14.61 \pm \\
0.83\end{array}$ & $\begin{array}{l}14.81 \pm \\
1.06\end{array}$ & $\begin{array}{l}14.54 \pm \\
0.75\end{array}$ & $\begin{array}{l}14.79 \pm \\
1.16\end{array}$ & $\begin{array}{l}14.80 \pm \\
1.62\end{array}$ & $\begin{array}{l}14.84 \pm \\
0.83\end{array}$ \\
\hline C18:3 & $\begin{array}{l}16.06 \pm \\
1.49\end{array}$ & $\begin{array}{l}11.79 \pm \\
0.55\end{array}$ & $\begin{array}{l}6.94 \pm \\
0.69\end{array}$ & $\begin{array}{l}6.92 \pm \\
0.73\end{array}$ & $\begin{array}{l}5.39 \pm \\
0.49\end{array}$ & $\begin{array}{l}4.40 \pm \\
0.80\end{array}$ & $\begin{array}{l}3.89 \pm \\
0.28\end{array}$ & $\begin{array}{l}3.40 \pm \\
0.64\end{array}$ & $\begin{array}{l}5.57 \pm \\
0.31\end{array}$ & $\begin{array}{l}4.42 \pm \\
1.05\end{array}$ & $\begin{array}{l}3.98 \pm \\
0.93\end{array}$ & $\begin{array}{l}3.69 \pm \\
0.49\end{array}$ & $\begin{array}{l}3.40 \pm \\
0.57\end{array}$ \\
\hline C20:4 & $\begin{array}{l}12.94 \pm \\
1.13\end{array}$ & $\begin{array}{l}12.61 \pm \\
0.86\end{array}$ & $\begin{array}{l}16.10 \pm \\
1.34\end{array}$ & $\begin{array}{l}19.48 \pm \\
1.57\end{array}$ & $\begin{array}{l}20.83 \pm \\
1.68\end{array}$ & $\begin{array}{l}21.69 \pm \\
1.82\end{array}$ & $\begin{array}{l}22.72 \pm \\
1.20\end{array}$ & $\begin{array}{l}23.62 \pm \\
1.63\end{array}$ & $\begin{array}{l}21.45 \pm \\
0.99\end{array}$ & $\begin{array}{l}22.42 \pm \\
1.60\end{array}$ & $\begin{array}{l}22.52 \pm \\
1.43\end{array}$ & $\begin{array}{l}22.95 \pm \\
1.74\end{array}$ & $\begin{array}{l}22.92 \pm \\
1.63\end{array}$ \\
\hline C20:5 & $\begin{array}{l}2.80 \pm \\
0.34\end{array}$ & $\begin{array}{l}3.00 \pm \\
0.61\end{array}$ & $\begin{array}{l}2.49 \pm \\
0.53\end{array}$ & $\begin{array}{l}2.65 \pm \\
0.48\end{array}$ & $\begin{array}{l}2.28 \pm \\
0.67\end{array}$ & $\begin{array}{l}1.96 \pm \\
0.45\end{array}$ & $\begin{array}{l}1.84 \pm \\
0.18\end{array}$ & $\begin{array}{l}1.71 \pm \\
0.34\end{array}$ & $\begin{array}{l}2.22 \pm \\
0.63\end{array}$ & $\begin{array}{l}1.90 \pm \\
0.44\end{array}$ & $\begin{array}{l}1.74 \pm \\
0.31\end{array}$ & $\begin{array}{l}1.68 \pm \\
0.52\end{array}$ & $\begin{array}{l}1.67 \pm \\
0.29\end{array}$ \\
\hline SFA & $\begin{array}{l}14.95 \pm \\
1.33\end{array}$ & $\begin{array}{l}15.11 \pm \\
0.87\end{array}$ & $\begin{array}{l}13.91 \pm \\
0.63\end{array}$ & $\begin{array}{l}13.85 \pm \\
1.29\end{array}$ & $\begin{array}{l}13.22 \pm \\
1.50\end{array}$ & $\begin{array}{l}12.41 \pm \\
1.73\end{array}$ & $\begin{array}{l}12.04 \pm \\
1.54\end{array}$ & $\begin{array}{l}11.74 \pm \\
1.62\end{array}$ & $\begin{array}{l}12.79 \pm \\
0.73\end{array}$ & $\begin{array}{l}11.86 \pm \\
0.91\end{array}$ & $\begin{array}{l}11.7 \pm \\
0.77\end{array}$ & $\begin{array}{l}11.54 \pm \\
1.26\end{array}$ & $\begin{array}{l}11.25 \pm \\
1.49\end{array}$ \\
\hline PUFA & $\begin{array}{l}45.05 \pm \\
2.11\end{array}$ & $\begin{array}{l}45.54 \pm \\
2.30\end{array}$ & $\begin{array}{l}42.35 \pm \\
2.57\end{array}$ & $\begin{array}{l}47.97 \pm \\
2.66\end{array}$ & $\begin{array}{l}45.83 \pm \\
2.34\end{array}$ & $\begin{array}{l}44.28 \pm \\
1.52\end{array}$ & $\begin{array}{l}43.72 \pm \\
1.44\end{array}$ & $\begin{array}{l}43.34 \pm \\
2.03\end{array}$ & $\begin{array}{l}44.05 \pm \\
1.88\end{array}$ & $\begin{array}{l}43.28 \pm \\
1.16\end{array}$ & $\begin{array}{l}43.03 \pm \\
1.28\end{array}$ & $\begin{array}{l}43.12 \pm \\
2.21\end{array}$ & $\begin{array}{l}42.83 \pm \\
3.07\end{array}$ \\
\hline
\end{tabular}


Table 5

Change in fatty acid content of L. bisecta SAG2043 with a low concentration of nitrogen (3.6 mM) under medium replacement cultivation over a time course. $3.6 \mathrm{mM}-3.6 \mathrm{mM}$, medium replacement from initial nitrogen concentration of $3.6 \mathrm{mM}$ to fresh medium of $3.6 \mathrm{mM}$ on day 9; $3.6 \mathrm{mM}$ $0 \mathrm{mM}$, medium replacement from initial nitrogen concentration of $3.6 \mathrm{mM}$ to fresh medium of $0 \mathrm{mM}$ on day 9

\begin{tabular}{|c|c|c|c|c|c|c|c|c|c|c|c|c|c|}
\hline \multirow[b]{2}{*}{ day } & \multicolumn{8}{|c|}{$3.6 \mathrm{mM}-3.6 \mathrm{mM}$} & \multicolumn{5}{|c|}{$3.6 \mathrm{mM}-0 \mathrm{mM}$} \\
\hline & 3 & 6 & 9 & 12 & 15 & 18 & 21 & 24 & 12 & 15 & 18 & 21 & 24 \\
\hline C16:0 & $\begin{array}{l}15.94 \pm \\
1.82\end{array}$ & $\begin{array}{l}13.16 \pm \\
1.54\end{array}$ & $\begin{array}{l}10.77 \pm \\
1.35\end{array}$ & $\begin{array}{l}11.46 \pm \\
0.69\end{array}$ & $\begin{array}{l}10.52 \pm \\
0.75\end{array}$ & $\begin{array}{l}9.76 \pm \\
1.20\end{array}$ & $\begin{array}{l}9.55 \pm \\
0.64\end{array}$ & $\begin{array}{l}9.59 \pm \\
0.77\end{array}$ & $\begin{array}{l}9.69 \pm \\
0.86\end{array}$ & $\begin{array}{l}9.10 \pm \\
0.94\end{array}$ & $\begin{array}{l}8.94 \pm \\
1.08\end{array}$ & $\begin{array}{l}8.91 \pm \\
1.30\end{array}$ & $\begin{array}{l}8.96 \pm \\
0.51\end{array}$ \\
\hline C18:0 & $\begin{array}{l}0.56 \pm \\
0.22\end{array}$ & $\begin{array}{l}1.42 \pm \\
0.37\end{array}$ & $\begin{array}{l}1.18 \pm \\
0.50\end{array}$ & $\begin{array}{l}1.73 \pm \\
0.59\end{array}$ & $\begin{array}{l}2.02 \pm \\
0.43\end{array}$ & $\begin{array}{l}2.04 \pm \\
0.75\end{array}$ & $\begin{array}{l}1.79 \pm \\
0.53\end{array}$ & $\begin{array}{l}1.94 \pm \\
0.40\end{array}$ & $\begin{array}{l}1.19 \pm \\
0.08\end{array}$ & $\begin{array}{l}2.33 \pm \\
0.63\end{array}$ & $\begin{array}{l}2.03 \pm \\
0.58\end{array}$ & $\begin{array}{l}2.30 \pm \\
0.63\end{array}$ & $\begin{array}{l}2.25 \pm \\
0.46\end{array}$ \\
\hline C18:1 & $\begin{array}{l}17.62 \pm \\
1.49\end{array}$ & $\begin{array}{l}34.27 \pm \\
2.08\end{array}$ & $\begin{array}{l}42.69 \pm \\
2.27\end{array}$ & $\begin{array}{l}37.79 \pm \\
2.41\end{array}$ & $\begin{array}{l}39.69 \pm \\
2.38\end{array}$ & $\begin{array}{l}41.14 \pm \\
1.42\end{array}$ & $\begin{array}{l}41.28 \pm \\
2.04\end{array}$ & $\begin{array}{l}41.22 \pm \\
1.64\end{array}$ & $\begin{array}{l}44.95 \pm \\
1.46\end{array}$ & $\begin{array}{l}44.08 \pm \\
2.31\end{array}$ & $\begin{array}{l}43.14 \pm \\
1.81\end{array}$ & $\begin{array}{l}42.68 \pm \\
1.66\end{array}$ & $\begin{array}{l}42.12 \pm \\
1.75\end{array}$ \\
\hline C18:2 & $\begin{array}{l}14.59 \pm \\
1.63\end{array}$ & $\begin{array}{l}13.68 \pm \\
1.40\end{array}$ & $\begin{array}{l}13.45 \pm \\
1.08\end{array}$ & $\begin{array}{l}13.17 \pm \\
0.94\end{array}$ & $\begin{array}{l}13.02 \pm \\
1.33\end{array}$ & $\begin{array}{l}12.87 \pm \\
1.21\end{array}$ & $\begin{array}{l}12.92 \pm \\
1.54\end{array}$ & $\begin{array}{l}13.14 \pm \\
0.96\end{array}$ & $\begin{array}{l}12.13 \pm \\
1.24\end{array}$ & $\begin{array}{l}11.89 \pm \\
1.53\end{array}$ & $\begin{array}{l}11.70 \pm \\
0.84\end{array}$ & $\begin{array}{l}11.81 \pm \\
0.67\end{array}$ & $\begin{array}{l}11.95 \pm \\
0.55\end{array}$ \\
\hline C18:3 & $\begin{array}{l}15.81 \pm \\
0.86\end{array}$ & $\begin{array}{l}7.95 \pm \\
1.32\end{array}$ & $\begin{array}{l}5.41 \pm \\
1.08\end{array}$ & $\begin{array}{l}5.75 \pm \\
0.63\end{array}$ & $\begin{array}{l}4.54 \pm \\
0.54\end{array}$ & $\begin{array}{l}3.92 \pm \\
0.37\end{array}$ & $\begin{array}{l}3.64 \pm \\
0.58\end{array}$ & $\begin{array}{l}3.45 \pm \\
0.39\end{array}$ & $\begin{array}{l}4.51 \pm \\
0.43\end{array}$ & $\begin{array}{l}3.92 \pm \\
0.91\end{array}$ & $\begin{array}{l}3.61 \pm \\
0.18\end{array}$ & $\begin{array}{l}3.42 \pm \\
0.50\end{array}$ & $\begin{array}{l}3.27 \pm \\
0.76\end{array}$ \\
\hline C20:4 & $\begin{array}{l}14.14 \pm \\
1.63\end{array}$ & $\begin{array}{l}18.38 \pm \\
1.28\end{array}$ & $\begin{array}{l}18.58 \pm \\
1.63\end{array}$ & $\begin{array}{l}22.33 \pm \\
1.55\end{array}$ & $\begin{array}{l}22.83 \pm \\
1.27\end{array}$ & $\begin{array}{l}23.18 \pm \\
2.30\end{array}$ & $\begin{array}{l}23.63 \pm \\
1.08\end{array}$ & $\begin{array}{l}24.02 \pm \\
2.11\end{array}$ & $\begin{array}{l}21.04 \pm \\
1.54\end{array}$ & $\begin{array}{l}22.56 \pm \\
1.27\end{array}$ & $\begin{array}{l}23.34 \pm \\
1.36\end{array}$ & $\begin{array}{l}24.79 \pm \\
1.09\end{array}$ & $\begin{array}{l}25.32 \pm \\
1.18\end{array}$ \\
\hline C20:5 & $\begin{array}{l}3.57 \pm \\
0.82\end{array}$ & $\begin{array}{l}2.80 \pm \\
0.75\end{array}$ & $\begin{array}{l}2.05 \pm \\
0.23\end{array}$ & $\begin{array}{l}2.61 \pm \\
0.34\end{array}$ & $\begin{array}{l}2.27 \pm \\
0.63\end{array}$ & $\begin{array}{l}2.04 \pm \\
0.74\end{array}$ & $\begin{array}{l}1.96 \pm \\
0.68\end{array}$ & $\begin{array}{l}1.92 \pm \\
0.54\end{array}$ & $\begin{array}{l}1.83 \pm \\
0.73\end{array}$ & $\begin{array}{l}1.70 \pm \\
0.49\end{array}$ & $\begin{array}{l}1.67 \pm \\
0.31\end{array}$ & $\begin{array}{l}1.68 \pm \\
0.27\end{array}$ & $\begin{array}{l}1.71 \pm \\
0.59\end{array}$ \\
\hline SFA & $\begin{array}{l}16.5 \pm \\
1.08\end{array}$ & $\begin{array}{l}14.58 \pm \\
1.55\end{array}$ & $\begin{array}{l}11.95 \pm \\
1.60\end{array}$ & $\begin{array}{l}13.19 \pm \\
1.33\end{array}$ & $\begin{array}{l}12.54 \pm \\
0.59\end{array}$ & $\begin{array}{l}11.8 \pm \\
0.67\end{array}$ & $\begin{array}{l}11.34 \pm \\
1.24\end{array}$ & $\begin{array}{l}11.53 \pm \\
1.48\end{array}$ & $\begin{array}{l}10.88 \pm \\
1.61\end{array}$ & $\begin{array}{l}11.43 \pm \\
0.88\end{array}$ & $\begin{array}{l}10.97 \pm \\
0.67\end{array}$ & $\begin{array}{l}11.21 \pm \\
1.54\end{array}$ & $\begin{array}{l}11.21 \pm \\
0.62\end{array}$ \\
\hline PUFA & $\begin{array}{l}48.11 \pm \\
2.13\end{array}$ & $\begin{array}{l}42.81 \pm \\
2.25\end{array}$ & $\begin{array}{l}39.49 \pm \\
2.77\end{array}$ & $\begin{array}{l}43.86 \pm \\
2.61\end{array}$ & $\begin{array}{l}42.66 \pm \\
2.84\end{array}$ & $\begin{array}{l}42.01 \pm \\
2.30\end{array}$ & $\begin{array}{l}42.15 \pm \\
2.66\end{array}$ & $\begin{array}{l}42.53 \pm \\
2.07\end{array}$ & $\begin{array}{l}39.51 \pm \\
1.59\end{array}$ & $\begin{array}{l}40.07 \pm \\
2.74\end{array}$ & $\begin{array}{l}40.32 \pm \\
1.11\end{array}$ & $\begin{array}{l}41.70 \pm \\
1.67\end{array}$ & $\begin{array}{l}42.25 \pm \\
3.01\end{array}$ \\
\hline
\end{tabular}

Table 6

The de novo assembly and annotation of transcriptome of $L$.

bisecta SAG2043

\begin{tabular}{|llll|}
\hline Assembly & \multicolumn{3}{c|}{ Annotation } \\
\hline Total Number & 43440 & COG & 4690 \\
\hline Total Length & 41805231 & GO & 5695 \\
\hline Mean Length & 962.37 & KEGG & 4404 \\
\hline N50 Length & 2833 & KOG & 6267 \\
\hline $200-300$ & $17294(39.81 \%)$ & Pfam & 8398 \\
\hline $300-500$ & $12004(27.63 \%)$ & Swiss-Prot & 6080 \\
\hline $500-1 \mathrm{kbp}$ & $5146(11.85 \%)$ & eggNOG & 9068 \\
\hline $1 \mathrm{kbp}-2 \mathrm{kbp}$ & $2930(6.74 \%)$ & Nr & 10116 \\
\hline$>2 \mathrm{kbp}$ & $6066(13.96 \%)$ & All annotated & 10655 \\
\hline
\end{tabular}

The content of AA (\% dry weight) in L. bisecta SAG2043 under different culture conditions showed an increasing trend with the prolongation of the culture time (Fig. 3a, b). Under the condition of ul-100, the difference of AA content with two different nitrogen concentrations was small during the early stage of the culture period, and the difference increased with the culture time. The AA content reached the maximum on the last day of the culture, accounting for $3.5 \%(18 \mathrm{mM})$ and $4.4 \%(3.6 \mathrm{mM})$ of the dry weight, respectively. Under ul-300, the AA accumulation rate under a low nitrogen concentration was much faster than it was under a high nitrogen concentration. The highest AA content under high and low nitrogen concentration was $5.4 \%$ and $6.5 \%$ of the dry weight, respectively. Compared to the AA content under ul- 100 , the AA content with the same nitrogen concentration was higher under ul-300. Under the bl-300, the change in the AA content was similar with other conditions, and the maximum content of AA reached $8.2 \%(18 \mathrm{mM})$ and $8.6 \%(3.6 \mathrm{mM})$ of the dry weight, respectively. For the treatments of culture medium replacement, the AA accumulation rate was slow during the early stage after replacement of the culture medium. The AA content first decreased and then increased in the treatment of $18 \mathrm{mM}-18 \mathrm{mM}(\mathrm{HN}-\mathrm{HN})$. For the treatments of $\mathrm{HN}-\mathrm{NF}$ and LN-LN, the AA accumulate rate increased slow, but the AA content under the treatment of LN-NF rapidly accumulated after the replacement of the old medium with fresh nitrogen-free 
medium. The AA content of all of the experimental treatments reached the maximum on the last day of the culture, accounting for $6.4 \%$ (HN$\mathrm{HN}$ ), $7.0 \%$ (HN-NF), 8.5\% (LN-LN) and 10.8\% (LN-NF) of dry weight, respectively. Light intensity and nitrogen concentration, as well as the replacement of medium, was able to change the AA content in the L. bisecta SAG2043. High light intensity and low nitrogen concentration accelerated $A A$ accumulation within the cells, and the replacement of culture medium further promoted the accumulation of AA.

\subsubsection{The proportion of AA within the lipid components of L. bisecta SAG2043}

We noticed that the change in the relative content of AA within the fatty acid content in some culture conditions was small (Table 2), whereas the AA content in terms of dry weight increased gradually. In order to explain such changes, the proportion of AA in the lipid content was determined. The lipid component was extracted from freeze-dried algae powder, and then the fatty acids within the lipid components were analyzed. The lipid composition was separated into neutral lipids (NLs), glycolipids (GLs) and phospholipids (PLs). The NLs content increased gradually with culture time, and GLs and PLs content decreased (Fig. 4a). GLs and PLs were major constituents of thylakoids, plasma membranes, and endoplasmic membrane systems, which perform a structural role. The NLs was mainly triacylglycerols, which served primarily as a storage form of carbon and energy. Under optimal growth conditions, microalgae synthesized fatty acids principally for esterification into membrane lipids, whereas cells accumulated NLs as energy sinks when it was under stress conditions [32]. On the last day of culture, NLs in L. bisecta SAG2043 reached $86.5 \%$ of the total lipids, and the relative content of GLs and PLs was $10.5 \%$ and $3.0 \%$ of the total lipids, respectively. The change in the AA distribution within the lipid composition showed that the AA proportion allocated in GLs and PLs decreased with the culture time, and AA proportion allocated in the NLs increased. The percentage of AA distributed within lipid compositions was $88.2 \%$ (NLs), $11.5 \%$ (GLs) and $0.3 \%$ (PLs), respectively. AA was mainly distributed in the NLs during the later period of the culture. In most species, nitrogen deficiency not only promoted lipid accumulation but also induced the synthesis of specific lipid compositions and lead to redistribution of fatty acids [23]. Unlike many microalgae contained PUFAs which were stored in polar lipids, L. bisecta SAG2043 could utilize NLs as a reservoir of AA, and simultaneously accumulated AA and NLs. This phenomenon was also observed in Lobosphaera (Parietochloris) incisa [6]. Moreover, Bigogno et al. [6] demonstrated that the capability to store long chain PUFAs in neutral lipids was a buffer capacity which allowed the microalgae to quickly adapt to the changing environment.

2.1.5 Effects of different nitrogen concentrations, light intensity and medium replacement on the lipid and AA productivity of L. bisecta SAG2043

Volumetric total lipid productivity is a combination of the biomass concentration and lipid content. It is considered as a key parameter to evaluate lipid production by microalgal strains [30]. Due to the opposite change in total lipid content (or AA content) and biomass under high and low nitrogen concentration, the difference in lipid (or AA) productivity under the two nitrogen concentrations was not significant (Fig. 5a). However, the effect of light intensity on lipid and AA productivity was significant. High light obviously improved total lipid and AA productivity, and the highest lipid and AA productivity was obtained in the culture exposed to bl-300. Under bl-300, the total lipid productivity with high nitrogen and low nitrogen concentration was $156.1 \mathrm{mg}^{-1} \mathrm{~L}^{-1}$ day ${ }^{-1}$ and $157.0 \mathrm{mg}^{-1} \mathrm{~L}^{-1}$ day $^{-1}$, respectively, and the AA productivity was $30.2 \mathrm{mg}^{-1} \mathrm{~L}^{-1}$ day $^{-1}$ and $29.0 \mathrm{mg}^{-1} \mathrm{~L}^{-1}$ day $^{-1}$, respectively. The replacement of culture medium increased the biomass concentration (HN-HN, $\mathrm{HN}-\mathrm{NF}$ ), whereas it prolonged the culture time, the total lipids and AA productivity, which was $136.0 \mathrm{mg}^{-1} \mathrm{~L}^{-1} \mathrm{day}^{-1}(\mathrm{HN}-\mathrm{HN}), 137.8 \mathrm{mg} \mathrm{L}^{-1}$ day $^{-1}(\mathrm{HN}-\mathrm{NF})$, and $23.8 \mathrm{mg}^{-1} \mathrm{~L}^{-1}$ day $^{-1}(\mathrm{HN}-\mathrm{HN}), 24.2 \mathrm{mg}^{-1} \mathrm{~L}^{-1}$ day $^{-1}(\mathrm{HN}-\mathrm{NF})$, respectively, were lower than those under culture without medium replacement (Fig. 2d). Both biomass and lipid content were significantly increased under low nitrogen concentration with medium replacement (LN-LN, LN-NF). The total lipid and AA productivity were higher compared to the culture without medium replacement. The total lipid productivity was $164.7 \mathrm{mg}^{-1} \mathrm{~L}^{-1}$ day $^{-1}(\mathrm{LN}-\mathrm{LN})$ and $171.7 \mathrm{mg}^{-1} \mathrm{~L}^{-1}$ day $^{-1}(\mathrm{LN}-\mathrm{NF})$, respectively, and the AA productivity was $30.7 \mathrm{mg}-1$ $\mathrm{L}^{-1}$ day $^{-1}(\mathrm{LN}-\mathrm{LN})$, and $34.4 \mathrm{mg}^{-1} \mathrm{~L}^{-1} \mathrm{day}^{-1}$ (LN-NF), respectively (Fig. $\left.5 \mathrm{~b}\right)$.

2.2 Transcriptome analysis of the novel oleaginous microalga L. bisecta SAG2043 revealed its potential mechanism for AA synthesis

The reference transcriptome of L. bisecta SAG2043 was sequenced and the double-ended sequencing was conducted using HiSeq X Ten highthroughput sequencing platform. A total of $16.81 \mathrm{~Gb}$ of clean reads were obtained. The number of unigenes after sequence assembly was 43,440 with N50 length of 2,833 bp (Table 1). For functional annotation, a total of 10,655 unigenes were annotated (Table 1).

To analyze the transcriptional response of L. bisecta SAG2043 under nitrogen deficiency, the cells grown under a high nitrogen concentration $(18 \mathrm{mM})$ and nitrogen-free conditions were collected on day 3 in culture, and RNA-seq for each sample were conducted (Table S1).

Acetyl coenzyme A (CoA) is an important precursor of de novo fatty acid synthesis. The source of Acetyl CoA in chloroplasts is probably produced by PDHC (pyruvate dehydrogenase complex) pathway. Pyruvate, which is the end-product of the Calvin cycle and glycolysis pathway, is directly catalyzed by the PDHC to form acetyl CoA (Fig. 6) [33]. PDHC is an enzyme complex composed of three enzymes and is critical for the supply of acetyl CoA. The expression of the PDHC gene located in chloroplasts was up-regulated in L. bisecta SAG2043. Specifically, three PDHC genes were identified (unigene_bmk.11837, unigene_bmk.12164, and unigene_bmk.8585), and the expression levels of all three genes were all up-regulated by more than 2-fold. $\mathrm{PDHC}$ provides adequate acetyl CoA to start the de novo synthesis of fatty acids, and the $\mathrm{CO}_{2}$ from decarboxylation of PDHC may also enter carbon fixation which increases the available carbon sources for fatty acid synthesis. 
Acetyl-CoA carboxylase (ACCase) is the first enzyme for the de novo synthesis of fatty acids and has been reported as a key rate-limiting enzyme, catalyzing the formation of malonyl-CoA from acetyl $\mathrm{CoA}$ and $\mathrm{HCO}_{3}{ }^{-}$[34]. Four ACCase genes were identified in $\mathrm{L}$. bisecta SAG2043 (Unigene_BMK.11695, Unigene_BMK.11856, Unigene_BMK.12421, Unigene_BMK.11794). ACCase was affected significantly by nitrogen starvation at the mRNA level, and the up-regulation of these genes may have a strong "traction" effect on the carbon flow into fatty acid synthesis. The malonyl group of malonyl-CoA is transferred to the acyl carrier protein (ACP) by the catalysis of malonyl CoA transacylase (MAT) to produce malonyl-ACP. As an important C2 unit donor in the whole fatty acid synthesis, the change of MAT expression was minimal. The fatty acid synthesis then goes through a cycle of reactions, including condensation, reduction, dehydration, and a re-reduction step catalyzed by fatty acid synthase (FAS), which mainly includes 3-ketoacyl-acp synthase (KAS), 3-ketoacyl-acp reductase (KAR), 3-ketoacyl-acp dehydrase (HAD), and 3-enyl-acp reductase (EAR) (Fig. 4) [35]. In SAG2043, there were 8 unigenes identified encoding FAS (Table S2). After seven cycles, the generated C16:0-ACP may be assembled into glycerolipids by an acyltransferase in chloroplasts or elongated to C18:0-ACP by KAS [35]. The first double bond is then introduced by the fatty-acyl-ACP desaturase (FAD), which may catalyze the formation of C16:1-ACP or C18:1-ACP. In SAG2043, 5 unigenes encoding FAD were identified, and they all used C18:0-ACP as a substrate. FAD, which catalyzed C16:0-ACP, was not found in the transcriptome. Accordingly, C16:1 could hardly be detected in the L. bisecta SAG2043, which was consistent with the composition of fatty acids.

The reaction catalyzed by the fatty-acyl-ACP thioesterase (FAT) hydrolyzes acyl-ACP to form free fatty acids will be output to the endoplasmic reticulum, where the reactions of carbon chain elongation, desaturation, and esterification occur [36]. There are two classes of thioesterases, FATA and FATB, which are responsible for hydrolyzing unsaturated and saturated acyl-ACPs, respectively [35]. In L. bisecta SAG2043, the expression of FATA with C18:1-ACP as the substrate was up-regulated significantly (Unigene_BMK.38890). Overall, the up-regulation and preference of FAD and FATA may be the reason that the oleic acid content was greatly increased and became the most abundant fatty acid under nitrogen deficiency in L. bisecta SAG2043. As such, it provided a precursor for subsequent long-chain PUFAs synthesis.

The fatty acid profile in L. bisecta SAG 2043 mainly included oleic acid (C18:1), linoleic acid (C18:2), linolenic acid (C18:3), AA (C20:4), and EPA (C20:5). Based on transcriptome annotation, we reconstructed the synthesis pathway of PUFAs in L. bisecta SAG 2043 (Fig. 6). There were two different pathways identified for the synthesis of AA $(C 20: 4, \omega-6)$ [37]. The first one was the conventional $\Delta 6$-pathway and the other one was the alternative $\triangle 8$-pathway in protists and some microalgae [38]. In plants, the synthesis of PUFAs starts with the formation of fatty acids catalyzed by a FAS complex in plastids. Stearic acid (SA, C18:0) is desaturated to oleic acid $\left(\mathrm{OA}, \mathrm{C} 18: 1^{\Delta 9}\right)$ by $\Delta 9$-desaturase [37], and then $\Delta 12$-desaturase is converted OA to linoleic acid (LA, C18:2 $\left.2^{\Delta 9,12}, \omega-6\right)$. In the conventional $\Delta 6$-pathway, the LA is converted to $y$-linolenic acid (GLA, C18:3 ${ }^{\Delta 6,9,12}$ ) by $\Delta 6$-desaturase, and GLA is then elongated to produce dihomo-y-linolenic acid (DGLA, C20:3 ${ }^{\Delta 8,11,14}$ ) by $\Delta 6$-elongase. Finally, $\Delta 5$-desaturase performs one more desaturation to produced $A A\left(C 20: 4^{\Delta 5,8,11,14}\right)$. In the alternative $\triangle 8$-pathway, the $\Delta 9$-elongase converts $L A$ to form eicosadienoic acid (EDA, C20:2 $2^{\Delta 11,14}$ ). Subsequently, EDA is desaturated to generate DGLA by $\triangle 8$-desaturase, which then yields AA by $\triangle 5$ desaturase. However, there was no $\triangle 8$-desaturase gene identified in L. bisecta SAG 2043. AA synthesis in L. bisecta SAG 2043 was by the conventional $\triangle 6$-pathway. According to the transcriptome analysis, there were 15 unigenes annotated as desaturases in L. bisecta SAG2043. Among them, the expression of 7 genes were up-regulated and 3 genes were down-regulated under the condition of nitrogen deficiency (Table S2). In L. bisecta SAG2043, there were no unigenes identified as a $\triangle 17$ desaturase, which illustrated that EPA may mainly form through an omega-3 pathway. Furthermore, it cut off the pathway from AA to EPA, so it was conducive to the accumulation of AA.

Nitrogen deficiency can significantly promote lipid accumulation (mainly TAG) in most microalgae. Acyl groups from Acyl-CoA are transferred to a different position of the glycerol-3-phosphate (G3P) involved in the four enzymatic steps, including glycerol-3-phosphate acyltransferase (GPAT) and lyso-phosphatidic acid acyltransferase (LPAT) to transfer the first and second acyl group into the sn-1 and sn-2 position of G3P to generate phosphatidic acid (PA), followed by dephosphorylation of phosphatidic acid phosphatase (PAP) to produce DAG, and a third acylation by diacyglycerol acyltransferase (DGAT). This is called the Kennedy pathway, which is shown in Fig. 6 . The classical Kennedy pathway is crucial for TAG synthesis in many species. According to the transcriptome analysis, the genes encoding three enzymes involved in the DAG synthesis pathway were identified in L. bisecta SAG2043 (Table S2). GPAT included two types-one located in the chloroplast and another located in the endoplasmic reticulum. There were 6 genes identified as LPATs in L. bisecta SAG2043. Among them, the expression of 4 genes was upregulated. It was previously reported that overexpression of the LPAT gene from Brassica napus in Arabidopsis resulted in a significant increase in the TAG content in the seeds [39]. Up regulation of LPAT may play a certain role in promoting TAG accumulation. Four PAP genes were identified in L. bisecta SAG2043, and all four transcripts were up-regulated. There are two main pathways for eukaryote to synthesize TAG from DAG depending on the acyl donor. One is acyl-CoA dependent pathway, and the other is acyl-CoA independent pathway. Both pathways use DAG as an acyl receptor. DGAT is a key enzyme that catalyzes the last and committed step in the acyl-CoA dependent pathway, which adds an acyl group from acyl-CoA to the sn-3 position of DAG. Two types of DGAT have been identified in microalgae. According to the transcriptome analysis of L. bisecta SAG2043, 5 unigenes encoding Type-2 DGAT (DGAT2) and 2 unigenes encoding Type-1 DGAT (DGAT1) were identified. The transcription abundance of DGAT2 was generally higher than that of DGAT1, and the expression level of all DGAT2 were up-regulated under nitrogen deficiency, indicating that DGAT2 plays a major role in TAG synthesis. Subcellular localization of DGAT was poorly understood. Thus, the synthesis of TAG in multiple organelles needs to be further explored. The acyl-CoA independent pathway uses phospholipids, such as 
phosphatidylcholine (PC) as acyl donors catalyzed by phospholipid:DAG acyltransferases (PDAT) to synthesize TAG. It has been reported that PDAT was a multifunctional enzyme in C. reinhardtii [40]. It has been shown to mediate membrane lipid turnover and TAG synthesis. Under low nitrogen stress, membrane lipids of algae degraded gradually with the accumulation of TAG, and the fluidity became worse [40]. Two PDAT genes were predicted in L. bisecta SAG2043, and the expression of PDAT with high transcriptional abundance was up-regulated by more than 2 times (group1_unigene_bmk.12161), which indicated that the PDAT pathway also contributed to the accumulation of TAG in L. bisecta SAG2043.

\section{Conclusion}

The coccoid green microalga Lobosphaera bisecta SAG 2043 has enormous potential for the production of lipids and AA. A low concentration of nitrogen and high intensity of light significantly promoted the accumulation of lipids and AA. The highest lipid and AA content reached $54.0 \%$ and $10.8 \%$ of the dry weight of L. bisecta SAG 2043 , respectively. Neutral lipids comprised $86.5 \%$ of the total lipids, and $88.2 \%$ of AA was distributed within the neutral lipids. We reconstructed the lipid metabolic pathways of L. bisecta SAG 2043 for the first time. Transcriptome analysis showed that multi-level regulation ensured the conversion efficiency of carbon to the synthesis of fatty acids, and up-regulation of key desaturases and elongases within the $\Delta 6$ pathway was conducive to the accumulation of fatty acids towards the synthesis of AA. The synthesis of oleic acid particularly ensured the supply of precursor to AA synthesis. Although L. bisecta SAG2043 has demonstrated a strong ability to accumulate oleic acid, its ability to convert oleic acid into AA was not as efficient as Lobosphaera incisa. Enhancing the ability of L. bisecta SAG 2043 to convert oleic acid to AA would improve the prospect of AA production from L. bisecta SAG2043.

\section{Materials And Methods}

\subsection{Algal strain and culture conditions}

Lobosphaera bisecta SAG2043 was obtained from Culture Collection of Algae at Göttingen University, Germany, and deposited in our laboratory at Jinan university. Cultures were maintained in modified BG-11 medium [11]. Initial synchronized cultures were grown in $250 \mathrm{~mL}$ Erlenmeyer flask with $150 \mathrm{~mL}$ working volume. The temperature was maintained at $(24 \pm 1){ }^{\circ} \mathrm{C}$.

4.2 Experimental design

4.2.1 Interactive effects of nitrogen concentrations and light intensities on the growth of L. bisecta SAG2043

The strain L. bisecta SAG2043 was cultured in mBG-11 medium with sodium nitrate used as the nitrogen source at two nitrogen concentrations of $18 \mathrm{mM}$ and $3.6 \mathrm{mM}$. Three lighting conditions were conducted as following: unilateral low light illumination of $100 \mu \mathrm{mol} \mathrm{m}^{-2} \mathrm{~s}^{-1}$ (ul-100), unilateral high light illumination of $300 \mu \mathrm{mol} \mathrm{m} \mathrm{m}^{-2} \mathrm{~s}^{-1}$ (ul-300), and bilateral high light illumination of $300 \mu \mathrm{mol} \mathrm{m} \mathrm{m}^{-2} \mathrm{~s}^{-1}$ (bl-300). The algae seed in logarithmic growth phase was collected by low-speed centrifugation at $1000 \times \mathrm{g}$ for 3 min and inoculated at an initial concentration of $\mathrm{OD}_{750}$ $=0.7 \pm 0.01$ in a $\varnothing 6.0 \mathrm{~cm} \times 60 \mathrm{~cm}$ bubble column glass photobioreactors $\left(1.3 \mathrm{~L}\right.$ working volume). The cultures were aerated with $1 \% \mathrm{CO}_{2}{ }^{-}$ enriched compressed air and exposed to 24 hours of continuous illumination. The temperature was maintained at $24 \pm 1^{\circ} \mathrm{C}$. Each experimental condition was performed in triplicate. The whole culture was grown for 15 days.

4.2.2 The effects of different nitrogen concentrations and medium replacement treatments on the growth of L. bisecta SAG2043

The mBG-11 medium was set with two initial nitrogen concentrations, $18 \mathrm{mM}$ and $3.6 \mathrm{mM}$. The light condition was ul-300. After 9 days of cultivation, the whole cultures were collected and centrifugated for removal of the old culture medium. The collected algal paste was reinoculated into the same column photobioreactors with fresh medium and cultivated for another 15 days. There were four medium replacement treatments. 1) The initial medium with a nitrogen concentration of $18 \mathrm{mM}$ was replaced with fresh medium which also had a nitrogen concentration of $18 \mathrm{mM}(18 \mathrm{mM}-18 \mathrm{mM}, \mathrm{HN}-\mathrm{HN})$. 2) The initial medium with a nitrogen concentration of $18 \mathrm{mM}$ was replaced with nitrogen-free fresh medium ( $18 \mathrm{mM}-0 \mathrm{mM}, \mathrm{HN}-\mathrm{NF})$. 3) The initial medium with a nitrogen concentration of $3.6 \mathrm{mM}$ was replaced with fresh medium containing $3.6 \mathrm{mM}$ of nitrogen (3.6 mM-3.6 mM, LN-LN). 4) The initial medium with a nitrogen concentration of $3.6 \mathrm{mM}$ was replaced with nitrogen-free fresh medium (3.6 mM-0 mM, LN-NF).

4.3 Analysis methods

\subsubsection{Biomass measurement}

$10 \mathrm{~mL}$ culture sample was filtered through pre-weighed glass fiber filter membrane with $0.45-\mu \mathrm{m}$ of pore size (dry weight, W1) by vacuum filter. The filter membranes containing algal cells were then dried in an oven at $105^{\circ} \mathrm{C}$ to constant weight (dry weight, W2). The dry weight of the algal cells was then calculated based on the difference between $\mathrm{W} 2$ and $\mathrm{W} 1$, divided by the volume of sampled algal suspension.

4.3.2 Lipid extraction and determination

Page $10 / 15$ 
Total lipid extraction was conducted based on method described by Khozin-Goldberg [12] with some modifications. About 50-80 mg of freezedried algal powder was extracted with $2 \mathrm{~mL}$ of dimethyl sulfoxide -methanol mixture $(\mathrm{V}: \mathrm{V}=1: 9)$ in a $50{ }^{\circ} \mathrm{C}$ water bath for $1.5 \mathrm{~h}$. The mixture was then centrifuged, and the supernatant was collected. The residue was re-extracted with $4 \mathrm{~mL}$ diethyl ether-hexane mixed solution $(\mathrm{V}: \mathrm{V}=1: 1)$ in an ice bath for $1.5 \mathrm{~h}$ and then centrifuged. The supernatant was collected into the same glass vial and the extraction process was repeated. The determination of lipid content was by gravimetric method and the detail was described in Gao et al. [11].

4.3.3 Fatty acids analysis

A total of $25 \mathrm{mg}$ dry weight of freeze-dried biomass was added to $2 \mathrm{~mL}$ methanol solution comprising $2 \% \mathrm{H}_{2} \mathrm{SO}_{4}(\mathrm{~V} / \mathrm{V})$ in a small vial, and then the vial was filled with argon gas. The mixture was incubated in a water bath at $80^{\circ} \mathrm{C}$ for $1.5 \mathrm{~h}$ in order to promote the transmethylation of fatty acids. The reaction was then quenched by adding the mixture of $1 \mathrm{~mL} \mathrm{H} 2 \mathrm{O}$ and $1 \mathrm{~mL}$ hexane. The solution was centrifuged at $3,500 \mathrm{rpm}(2,740$ $\times \mathrm{g}$ ) for $5 \mathrm{~min}$, and the upper layer was then dried with $\mathrm{N}_{2}$, followed by addition of $100 \mu \mathrm{L}$ hexane. Heptadecanoic acid (Sigma Chemical Co., USA) was used as an internal standard. The fatty acid methyl esters (FAMEs) were analyzed with gas chromatography (GC) on an Agilent Gas Chromatograph (Agilent 6890N GC, Agilent Technologies, USA) and authentic standards. Detailed procedure for GC analysis has been described by Gao et al [11].

\subsubsection{Separation of lipid fractions and quantification}

The aforementioned lipid extracts were loaded on a solid-phase silica gel column (Sep-Pak Plus Silica, Waters) and then separated to neutral lipids (NLs), glycolipids (GLs), and phospholipids (PLs) using the method described by Christie and Han [13]. The column was equilibrated with chloroform, and then, the lipid extracts were dissolved in chloroform and loaded onto the column. Three sequential eluting solvents were used that was chloroform isolated the neutral lipids (NLs), acetone/methanol (9:1, v/v) isolated the glycolipids (GLs), and methanol isolated phospholipids (PLs), respectively. Each fraction was dried under $\mathrm{N}_{2}$ flow and weighed.

4.3.5 RNA extraction, library construction, sequencing, assembly and functional annotation

To learn the transcriptome changes of L. bisecta SAG2043 during the lipid accumulation, RNA-seq analysis was performed using + N (18 mM, $\mathrm{NR})$ and $-\mathrm{N}(0 \mathrm{mM}, \mathrm{NF})$ samples derived from day 3 cultures. Total RNA of samples was extracted by method of RNAiso Plus (TaKaRa Biotech Co., Beijing, China). The detailed procedure of cDNA library construction had been described in Huang et al. [14]. RNA sequencing of each sample was conducted using an Illumina HiSeq 4000 by BioMarker Technologies Co. (Beijing, China). The raw files were available from the NCBI SRA database under the accession number: PRJNA594119. The transcriptome was assembled using Trinity software [15]. The assembled genes were annotated using the BLASTx with an E-value threshold of $1.0 \mathrm{E}^{-5}$ against the databases as follows: NR (NCBI non-redundant protein sequences), COG (Clusters of Orthologous Groups of proteins), Swiss-Prot, KEGG (Kyoto Encyclopedia of Genes and Genomes), and GO (Gene Ontology).

\section{Abbreviations}

AA:arachidonic acid; TAG:triacylglycerol; LC-PUFA:Iong chain polyunsaturated fatty acid; FAMEs:fatty acid methyl esters; NLs:neutral lipids; GLs:glycolipids; PLs:phospholipids; ACP:acyl carrier protein; 3-PGA:3-phosphoglycerate; G-3-P:glycerol-3-phosphate; PDHC:pyruvate dehydrogenase complex; ACCase:acetyl-CoA carboxylase; MAT:malonyl CoA transacylase; ACP:acyl carrier protein; KAS:3-ketoacyl-acp synthase; KAR:3-ketoacyl-acp reductase; HAD:3-ketoacyl-acp dehydrase; EAR:3-enyl-acp reductase; FAD:fatty-acyl-ACP desaturase; FAT:fatty-acyl-ACP thioesterase; D:desaturase; E:elongase; GPAT:glycerol-3-phosphate acyltransferase; LPAT:lyso-phosphatidic acid acyltransferase; PA:phosphatidic acid; PAP:phosphatidic acid phosphatase; DAG:diacylglycerol; DGAT:diacyglycerol acyltransferase; PC:phosphatidylcholine; PE:phosphatidylethanolamine; PDAT:phospholipid:DAG acyltransferases;ul-100:unilateral low light illumination of $100 \mu \mathrm{mol}^{-2} \mathrm{~s}^{-1}$; ul300:unilateral high light illumination of $300 \mu \mathrm{mol} \mathrm{m} \mathrm{m}^{-2} \mathrm{~s}^{-1}$; bl-300:bilateral high light illumination of $300 \mu \mathrm{mol} \mathrm{m}{ }^{-2} \mathrm{~s}^{-1} ; 18 \mathrm{mM}-18 \mathrm{mM}, \mathrm{HN}-$ $\mathrm{HN}$ :The initial medium with a nitrogen concentration of $18 \mathrm{mM}$ was replaced with fresh medium which also had a nitrogen concentration of $18 \mathrm{mM}$ on day 9; $18 \mathrm{mM}-0 \mathrm{mM}, \mathrm{HN}-\mathrm{NF}$ :The initial medium with a nitrogen concentration of $18 \mathrm{mM}$ was replaced with nitrogen-free fresh medium on day $9 ; 3.6 \mathrm{mM}-3.6 \mathrm{mM}$, LN-LN:The initial medium with a nitrogen concentration of $3.6 \mathrm{mM}$ was replaced with fresh medium containing $3.6 \mathrm{mM}$ of nitrogen on day 9; $3.6 \mathrm{mM}-0 \mathrm{mM}$, LN-NF:The initial medium with a nitrogen concentration of $3.6 \mathrm{mM}$ was replaced with nitrogen-free fresh medium on day 9.

\section{Declarations}

\section{Authors' contributions}

Ideation and design of experiment was done by $\mathrm{CZ}$ and BG; development and optimization of experimental methods was done by BG and LH; collection of experiment data was done by BG, $\mathrm{XL}$, and GM. preparation and writing of the manuscript was done by $\mathrm{BG}$, LH, JL and CZ.

\section{Acknowledgements}


Not applicable

\section{Funding}

This work was supported by the Sinopec joint program of China Petroleum and Chemical Corporation (contract number: ST18005-2), the Guangzhou science and technology innovation program (201907010005), the Fundamental Research Funds for the Central Universities (21619305) and the Blue Life of Scientific and Technological Innovation Project Financially Supported by Qingdao National Laboratory for Marine Science and Technology (MS2019N001).

\section{Competing interests}

The authors declare that they have no competing interests. All authors agree to authorship and approved the final manuscript.

\section{Ethics approval and consent to participate}

Not applicable.

\section{Consent for publication}

The authors have consented for publication.

\section{Availability of supporting data}

The authors promise the availability of supporting data.

\section{References}

[1] Shanab SM, Hafez RM, Fouad AS. A review on algae and plants as potential source of arachidonic acid. J Adv Res. 2018;11:3-13.

[2] Ji XJ, Ren LJ, Nie ZK, Huang H, Ouyang PK. Fungal arachidonic acid-rich oil: research, development and industrialization. Crit Rev Biotechnol. 2014;34(3):197-214.

[3] Hanna VS, Hafez EAA. Synopsis of arachidonic acid metabolism: A review. J Adv Res. 2018;11:23-32.

[4] Xue WB, Liu F, Sun Z, Zhou ZG. A $\Delta-9$ fatty acid desaturase gene in the microalga Myrmecia incisa Reisigl: cloning and functional analysis. Int J Mol Sci. 2016;17(7):1143.

[5] Khan MI, Shin JH, Kim JD. The promising future of microalgae: current status, challenges, and optimization of a sustainable and renewable industry for biofuels, feed, and other products. Microb Cell Fact. 2018;17(1):36.

[6] Bigogno C, Khozin-Goldberg I, Boussiba S, Vonshak A, Cohen Z. Lipid and fatty acid composition of the green oleaginous alga Parietochloris incisa, the richest plant source of arachidonic acid. Phytochemistry. 2002;60(5):497-

[7] Ward OP, Singh A. Omega-3/6 fatty acids: Alternative sources of production. Process Biochem. 2005;40:3627-3652.

[8] Lang I, Hodac L, Friedl T, Feussner I. Fatty acid profiles and their distribution patterns in microalgae: a comprehensive analysis of more than 2000 strains from the SAG culture collection. BMC Plant Biol. 2011;11(1):124.

[9] Khotimchenko SV. Lipids from the marine alga Gracilaria verrucosa. Chem Nat Compd+. 2005;41(3):285-288.

[10] Řezanka T, Lukavský J, Nedbalová L, Sigler K. Production of structured triacylglycerols from microalgae. Phytochemistry. 2014;104:95-104.

[11] Gao B, Yang J, Lei X, et al. Characterization of cell structural change, growth, lipid accumulation, and pigment profile of a novel oleaginous microalga, Vischeria stellata (Eustigmatophyceae), cultured with different initial nitrate supplies. J Appl Phycol. 2016;28(2):821-830.

[12] Khozin-Goldberg I, Shrestha P, Cohen Z. Mobilization of arachidonyl moieties from triacylglycerols into chloroplastic lipids following recovery from nitrogen starvation of the microalga Parietochloris incisa. Biochimica et Biophysica Acta (BBA)-Molecular and Cell Biology of Lipids. 2005;1738(1-3): 63-71.

[13] Christie WW, Han X. Analysis of simple lipid classes. In: Christie WW, Han X, editors. Lipid Analysis. 4rd ed. Woodhead Publishing. 2012. p. 69-90. 
[14] Huang L, Gao B, Wu M, Wang F, Zhang C. Comparative transcriptome analysis of a long-time span two-step culture process reveals a potential mechanism for astaxanthin and biomass hyper-accumulation in Haematococcus pluvialis JNU35. Biotechnol Biofuels. 2019;12(1):18.

[15] Grabherr MG, Haas BJ, Yassour M, Levin JZ, Thompson DA, Amit I, Chen Z. Full-length transcriptome assembly from RNA-Seq data without a reference genome. Nat Biotechnol. 2011;29(7): 644.

[16] Salama ES, Hwang JH, El-Dalatony MM, Kurade MB, Kabra AN, Abou-Shanab RA, ... Jeon BH. Enhancement of microalgal growth and biocomponent-based transformations for improved biofuel recovery: a review. Bioresour Technol. 2018;258:365-375.

[17] Kitaya Y, Azuma $\mathrm{H}$, Kiyota M. Effects of temperature, $\mathrm{CO}_{2} / \mathrm{O}_{2}$ concentrations and light intensity on cellular multiplication of microalgae, Euglena gracilis. Adv Space Res. 2005;35(9):1584-1588.

[18] Ran W, Wang H, Liu Y, Qi M, Xiang Q, Yao C, ... Lan X. Storage of starch and lipids in microalgae: biosynthesis and manipulation by nutrients. Bioresour Technol. 2019;121894.

[19] Wan C, Bai FW, Zhao XQ. Effects of nitrogen concentration and media replacement on cell growth and lipid production of oleaginous marine microalga Nannochloropsis oceanica DUT01. Biochem Eng J. 2013;78:32-38.

[20] Sun H, Liu B, Lu X, Cheng KW, Chen F. Staged cultivation enhances biomass accumulation in the green growth phase of Haematococcus pluvialis. Bioresour Technol. 2017;233:326-331.

[21] Wang F, Gao B, Wu M, Huang L, Zhang C. A novel strategy for the hyper-production of astaxanthin from the newly isolated microalga Haematococcus pluvialis JNU35. Algal Res. 2019;39:101466.

[22] Aratboni HA, Rafiei N, Garcia-Granados R, Alemzadeh A, Morones-Ramírez JR. Biomass and lipid induction strategies in microalgae for biofuel production and other applications. Microb Cell Fact. 2019;18(1):178.

[23] Lari Z, Moradi-kheibari N, Ahmadzadeh H, Abrishamchi P, Moheimani NR, Murry MA. Bioprocess engineering of microalgae to optimize lipid production through nutrient management. J Appl Phycol. 2016;28(6):3235-3250.

[24] Nigam S, Rai MP, Sharma R. Effect of nitrogen on growth and lipid content of Chlorella pyrenoidosa. Am J Biochem Biotechnol. 2011;7:126131.

[25] Ho SH, Huang SW, Chen CY, Hasunuma T, Kondo A, Chang JS. Bioethanol production using carbohydrate-rich microalgae biomass as feedstock. Bioresour Technol. 2013;135:191-198.

[26] Fon-Sing S, Borowitzka MA. Isolation and screening of euryhaline Tetraselmis spp. suitable for large-scale outdoor culture in hyper saline media for biofuels. J Appl Phycol. 2016;28:1-14.

[27] Liu J, Yuan C, Hu G, Li F. Effects of light intensity on the growth and lipid accumulation of microalga Scenedesmus sp. 11-1 under nitrogen limitation. Appl Biochem Biotech. 2012;166(8):2127-2137.

[28] Takeshita T, Ota S, Yamazaki T, Hirata A, Zachleder V, Kawano S. Starch and lipid accumulation in eight strains of six Chlorella species under comparatively high light intensity and aeration culture conditions. Bioresour Technol. 2014;158:127-134.

[29] Feng D, Chen Z, Xue S, et al. Increased lipid production of the marine oleaginous microalgae Isochrysis zhangjiangensis (Chrysophyta) by nitrogen supplement. Bioresour Technol. 2011;102(12):6710-6716.

[30] Breuer G, Lamers PP, Martens DE, Draaisma RB, Wijffels RH. The impact of nitrogen starvation on the dynamics of triacylglycerol accumulation in nine microalgae strains. Bioresour Technol. 2012;124:217-226.

[31] Lee S, Lim SR, Jeong DG, Kim JH. Characterization of an Oleaginous Unicellular Green Microalga, Lobosphaera incisa (Reisigl, 1964) Strain K-1, Isolated From a Tidal Flat in the Yellow Sea, Republic of Korea. Front Microbiol. 2018;9.

[32] Klok AJ, Martens DE, Wijffels RH, Lamers PP. Simultaneous growth and neutral lipid accumulation in microalgae. Bioresour Technol. 2013;134:233-243.

[33] Tovar-Méndez A, Miernyk JA, Randall DD. Regulation of pyruvate dehydrogenase complex activity in plant cells. Eur J Biochem. 2003;270(6):1043-1049. 
[34] Lenka SK, Carbonaro N, Park R, Miller SM, Thorpe I, Li Y. Current advances in molecular, biochemical, and computational modeling analysis of microalgal triacylglycerol biosynthesis. Biotechnol Adv. 2016;34(5):1046-1063.

[35] Li Y, Han D, Yoon K, Zhu S, Sommerfeld M, Hu Q. Molecular and cellular mechanisms for lipid synthesis and accumulation in microalgae: biotechnological implications. Handbook of microalgal culture, 2013; 545-565.

[36] Chapman KD, Ohlrogge JB. Compartmentation of triacylglycerol accumulation in plants. J Biological Chemistry. 2012;287(4):2288-2294.

[37] Ruiz-Lopez N, Usher S, Sayanova OV, Napier JA, Haslam RP. Modifying the lipid content and composition of plant seeds: engineering the production of LC-PUFA. Appl Microbiol Biotechnol. 2015;99(1):143-154.

[38] Wallis JG, Browse J. The $\Delta 8$-desaturase of Euglena gracilis: an alternate pathway for synthesis of 20-carbon polyunsaturated fatty acids. Arch Biochem Biophys. 1999;365:307-16.

[39] Maisonneuve S, Bessoule JJ, Lessire R, Delseny M, Roscoe TJ. Expression of rapeseed microsomal lysophosphatidic acid acyltransferase isozymes enhances seed oil content in Arabidopsis. Plant Physiol. 2010;152(2):670-684.

[40] Yoon K, Han D, Li Y, Sommerfeld M, Hu Q. Phospholipid: diacylglycerol acyltransferase is a multifunctional enzyme involved in membrane lipid turnover and degradation while synthesizing triacylglycerol in the unicellular green microalga Chlamydomonas reinhardtii. The Plant Cell. 2012;24(9):3708-3724.

\section{Figures}

\section{Figure 1}

The effect of different culture conditions on the growth of L. bisecta SAG2043; ul, unilateral illumination; bl, bilateral illumination; 100,300 , light intensity ( $\mu \mathrm{mol} \mathrm{m}-2 \mathrm{~s}-1) ; 18 \mathrm{mM}, 3.6 \mathrm{mM}$, nitrogen concentration; $18 \mathrm{mM}-18 \mathrm{mM}$, medium replacement from initial nitrogen concentration of 18 $\mathrm{mM}$ to fresh medium of $18 \mathrm{mM}$ on day $9 ; 18 \mathrm{mM}-0 \mathrm{mM}$, medium replacement from initial nitrogen concentration of $18 \mathrm{mM}$ to fresh medium of 0 $\mathrm{mM}$ on day 9; $3.6 \mathrm{mM}-3.6 \mathrm{mM}$, medium replacement from initial nitrogen concentration of $3.6 \mathrm{mM}$ to fresh medium of $3.6 \mathrm{mM}$ on day 9; $3.6 \mathrm{mM}$ $0 \mathrm{mM}$, medium replacement from initial nitrogen concentration of $3.6 \mathrm{mM}$ to fresh medium of $0 \mathrm{mM}$ on day 9 .

$\vec{A}$

\section{Figure 2}

The effect of different culture conditions on lipid content of L. bisecta SAG2043.

as

Figure 3

Change in the AA content of L. bisecta SAG2043 under different culture conditions over a time course.

CA

\section{Figure 4}

Change in the contents of each lipid composition (neutral lipid (NL), glycolipids (GL) and phospholipids (PL)) (a) and arachidonic acid content in different lipid fractions (b) under low nitrogen concentration (3.6 mM) over a time course.

as

Figure 5

Change in the productivity of the volumetric total lipid and arachidonic acid of L. bisecta in different culture conditions over a time course.

D.

\section{Figure 6}

Fatty acid and triacylglycerol (TAG) biosynthesis pathways in L. bisecta SAG2043. Enzyme abbreviations are as follows: 3-PGA, 3phosphoglycerate; G-3-P, glycerol-3-phosphate; PDHC, pyruvate dehydrogenase complex; ACCase, acetyl-CoA carboxylase; MAT, malonyl CoA transacylase; ACP, acyl carrier protein; KAS, 3-ketoacyl-acp synthase; KAR, 3-ketoacyl-acp reductase; HAD, 3-ketoacyl-acp dehydrase; EAR, 3-enyl- 
acp reductase; FAD, fatty-acyl-ACP desaturase; FAT, fatty-acyl-ACP thioesterase; D, desaturase; E, elongase; GPAT, glycerol-3-phosphate acyltransferase; LPAT, lyso-phosphatidic acid acyltransferase; PA, phosphatidic acid; PAP, phosphatidic acid phosphatase; DAG, diacylglycerol; DGAT, diacyglycerol acyltransferase; PC, phosphatidylcholine; PE, phosphatidylethanolamine; PDAT, phospholipid:DAG acyltransferases.

\section{Supplementary Files}

This is a list of supplementary files associated with this preprint. Click to download.

- Tables1.doc

- Tables2.xls 